\title{
Dynamics of Non-Isothermal Pressure-Driven Flow of Generalized Viscoelastic-Fluid-Based Nanofluids in a Channel
}

\author{
Idrees Khan, ${ }^{1,2}$ Tiri Chinyoka $\mathbb{D}^{1,2}$ and Andrew Gill ${ }^{3}$ \\ ${ }^{1}$ Centre for Research in Computational \& Applied Mechanics, University of Cape Town, Rondebosch 7701, \\ Cape Town, South Africa \\ ${ }^{2}$ Department of Mathematics and Applied Mathematics, University of Cape Town, Rondebosch 7701, Cape Town, South Africa \\ ${ }^{3}$ Centre for High Performance and Computing, Council for Scientific and Industrial Research, Rosebank 7700, \\ Cape Town, South Africa
}

Correspondence should be addressed to Tiri Chinyoka; tchinyok@vt.edu

Received 28 December 2021; Accepted 21 January 2022; Published 7 February 2022

Academic Editor: Ahmed Zeeshan

Copyright (c) 2022 Idrees Khan et al. This is an open access article distributed under the Creative Commons Attribution License, which permits unrestricted use, distribution, and reproduction in any medium, provided the original work is properly cited.

\begin{abstract}
The investigation considers numerical analysis and computational solution of unsteady, pressure-driven channel flow of a generalized viscoelastic-fluid-based nanofluid (GVFBN) subject to exothermic reactions. Temperature-dependent fluid thermal conductivity is considered, and the flow is subject to convective cooling at the walls. The non-isothermal generalized Giesekus constitutive model is employed for the GVFBN. A Carreau model is used to describe the shear-rate dependence of fluid viscosity, and exothermic reactions are assumed to follow Arrhenius kinetics. An efficient semi-implicit numerical technique based on the finite-difference method is applied to obtain computational solutions to the model equations. The computational methodologies are built into the MATLAB software. The effects of various fluid and flow parameters, specifically the nanoparticle volume fraction, are explored. The results demonstrate that those parameters which only directly couple to the energy equation (but are otherwise indirectly coupled to momentum and stress-constitutive equations, say via the temperature-dependent viscosities and relaxation times) would only show prominent effects on fluid temperature but not on the fluid velocity or the polymer stresses. The results also demonstrate, as in the literature on exothermic flows, that the values of exothermic-reaction parameter must be carefully controlled as large values would lead to thermal runway phenomena. The illustrated results are consistent with the existing literature and additionally add novel new contributions to non-isothermal and pressure-driven channel flow of GVFBN under convective cooling conditions.
\end{abstract}

\section{Introduction}

A mixture of metallic (silver, copper, etc.) nanometre-sized particles suspended in a conventional base fluid (water, oil, etc.) is referred to as a nanofluid. For a comprehensive description of nanofluids and their utility, say, in the heattransfer-rate (HTR) characteristics, the reader is referred to, say, [1].

Optimal material conditions for fluid viscosity and thermal conductivity may be enhanced by simultaneously using several types of nanoparticles (say three different types) of various shapes, sizes, density, etc. in the same nanofluid mixture (see, for example, [2, 3]). The present research focuses on the effects of shear-dependent viscosity and fluid elasticity and hence will use homogeneous nanoparticles of one kind for illustrative purposes.

Similar investigations, as in [1], on thermodynamic properties and effects of various types of nanofluids have been conducted, say in [4-24]. The importance of such investigations cannot be overstated, especially considering the novel applications of nanofluids to thermal conductivity and HTR improvement, microfluidics, fuel-cell development, chemotherapy, thermal storage, electronic cooling and heating, etc.

A vast majority of the research on nanofluid flow has been conducted with Newtonian base fluids. The recent developments in non-isothermal constitutive models for viscoelastic fluid flow and their related applications (see, for 
example, $[1,25-30])$ have made it possible for the extension of the Newtonian-based fluid models to more general nonNewtonian (and specifically viscoelastic)-fluid-based nanofluids. The current work represents such an extension to viscoelastic nanofluidics, specifically using GVFBN.

The extensions to more general non-Newtonian-fluidbased nanofluids are not simply a theoretical and mathematical nicety but are rather driven by the vast and contemporary relevance to industrial, technological, and medical applications of non-Newtonian fluids in general and viscoelastic fluids in particular (see [31]). The work in [1] focused on novel development and analysis of GVFBN in shear-driven isobaric flows. The current work extends this analysis to non-isobaric (pressure-driven) channel flow of GVFBN. Additionally, instead of the isothermal wall boundary conditions employed in [1], the current work explores symmetrical convective cooling on the channel walls.

The paper is organized in the following sequence. Section 2 summarizes the model and governing equations. Section 3 gives the numerical algorithms and computational methodologies for the model problem as well as preliminary test results on temporal and spatial convergence. The exploration and discussion of the effects of the various embedded parameters are detailed in Section 4. Concluding remarks are given in Section 5 .

\section{Problem Formulation}

The schematic of the model problem is displayed in Figure 1.

An incompressible GVFBN is subjected to unsteady, laminar, and pressure-driven flow in a channel formed by two infinitely long parallel walls. The GVFBN is assumed to have both variable shear viscosity and variable thermal conductivity and is susceptible to exothermic reactions following Arrhenius theory. The $x^{*}$-axis is considered parallel to the flow direction and the $y^{*}$-axis is perpendicular to it.

Following the model developments in [1], the appropriate dimensionless parameters of current interest are the Reynolds number ( $\mathrm{Re})$, ambient-temperature parameter $\left(\theta_{a}\right)$, Brinkman number $(\mathrm{Br})$, Deborah number (De), activation-energy parameter $(\alpha)$, Prandtl number (Pr), Peclet number $(\mathrm{Pe}=\mathrm{Re} \cdot \mathrm{Pr})$, Frank-Kamenetskii parameter $\left(\delta_{1}\right)$, Biot number $(\mathrm{Bi})$, and the ratio of the polymer-to-the-total viscosity $(\beta)$ :

$$
\begin{gathered}
\beta=\frac{\eta_{p}^{*}}{\eta^{*}}, \\
\operatorname{De}=\frac{\lambda_{0}^{*} U_{0}^{*}}{h^{*}}, \\
\operatorname{Re}=\frac{\rho_{f}^{*} U_{0}^{*} a^{*}}{\eta^{*}}, \\
\operatorname{Pr}=\frac{c_{p f}^{*} \eta^{*}}{\kappa_{f}^{*}},
\end{gathered}
$$

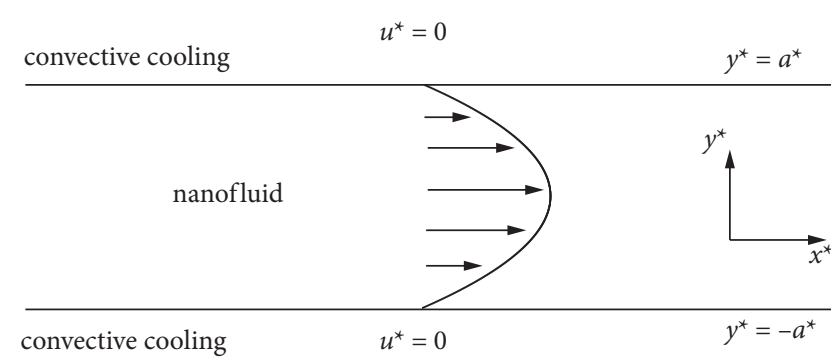

FIGURE 1: Geometry of the model problem.

$$
\begin{aligned}
\theta_{a} & =\frac{T^{*}-T_{0}^{*}}{\alpha T_{0}^{*}}, \\
B r & =\frac{\eta^{*} U_{0}^{* 2}}{\kappa_{f}^{*} \alpha T_{0}^{*},} \\
B i & =\frac{h^{*} a^{*}}{k_{0}^{*}}, \\
\operatorname{Re}_{n f} & =\frac{\rho_{n f}}{\rho_{f}} \operatorname{Re}, \\
P e_{n f} & =\frac{\left(\rho c_{p}\right)_{n f}}{\left(\rho c_{p}\right)_{f}} P e, \\
\alpha & =\frac{R^{*} T_{0}^{*}}{E^{*}}, \\
\delta_{1} & =\frac{Q^{*} A^{*} C^{*} a^{* 2}}{\kappa_{f}^{*} R^{*} T_{W}^{* 2}} \exp \left(-\frac{1}{\alpha}\right) .
\end{aligned}
$$

The nanofluid quantities $(n f)$ are obtained from linear combinations of the volume fractions $(\varphi)$ of the base fluid $(f)$ and of the solid nanoparticles (s), e.g.,

$$
\begin{aligned}
\rho_{n f} & =\varphi \rho_{s}+(1-\varphi) \rho_{f}, \\
\left(\rho c_{p}\right)_{n f} & =\varphi\left(\rho c_{p}\right)_{s}+(1-\varphi)\left(\rho c_{p}\right)_{f} .
\end{aligned}
$$

The appropriate dimensionless governing equations are

$$
\nabla \cdot u=0
$$

$$
\begin{aligned}
\operatorname{Re}_{n f} \frac{D u}{D t} & =-\operatorname{Re}_{n f} \nabla p+\nabla \cdot(\sigma), \\
\operatorname{Pe}_{n f} \frac{D T}{D t} & =-\nabla \cdot\left(\kappa_{n f} \nabla T\right)+\operatorname{BrQ}_{D}+\delta_{1} \exp \left(\frac{T}{1+\alpha T}\right), \\
& \tau+\varepsilon \tau^{2}+\operatorname{De} \bar{\lambda}(T)\left[\frac{\nabla}{\tau}-\tau \frac{D}{D t}(\ln (1+\alpha T))\right] \\
= & \frac{\eta_{p}(T)}{(\sqrt{1-\varphi})^{5}} S,
\end{aligned}
$$

with 


$$
\begin{aligned}
& \sigma=\tau+\frac{\eta_{s}(T)}{(\sqrt{1-\varphi})^{5}} S, \\
& S=\nabla u+(\nabla u)^{T}, \\
& \stackrel{\nabla}{\tau}=\frac{D \tau}{D t}-\nabla u \cdot \tau-\tau \cdot(\nabla u)^{T} .
\end{aligned}
$$

The dimensionless dissipation term for the single-mode non-isothermal Giesekus model is

$$
Q_{D}=\frac{\eta_{s}(T)}{(\sqrt{1-\varphi})^{5}} S: \nabla u+\gamma S: \tau+(1-\gamma) \frac{\widehat{G}}{2 D e \bar{\lambda}(T)}\left(I_{1}+\operatorname{Tr}\left(b^{-1}\right)-6\right)
$$

where the polymeric-stress tensor $(\tau)$ and conformation tensor (b) are related by

$$
\tau=\widehat{G}(b-I) .
$$

The dimensionless temperature-dependent viscosities, thermal conductivity, and relaxation times are

$$
\begin{aligned}
\eta_{s}(T) & =(1-\beta) \exp (-\alpha T),\left(\eta_{s}\right)_{n f}=\frac{\eta_{s}(T)}{(\sqrt{1-\varphi})^{5}} \\
\eta_{p}(\dot{\gamma}, T) & =\left[\beta+(m-1)\left(1+(\lambda \dot{\gamma})^{2}\right)^{n-1 / 2}\right] e^{(-\alpha T)}, \\
\left(\eta_{p}\right)_{n f} & =\frac{\eta_{p}(\dot{\gamma}, T)}{(\sqrt{1-\varphi})^{5}},
\end{aligned}
$$

with

$$
\begin{aligned}
\eta & =\eta_{s}(T)+\eta_{p}(\dot{\gamma}, T), \\
\eta_{n f} & =\frac{\eta}{(\sqrt{1-\varphi})^{5}}, \\
\bar{\lambda}(T) & =\frac{1}{1+\alpha T} \exp (-\alpha T), \\
\kappa_{n f} & =\frac{\kappa_{s}+(1-\aleph) \kappa_{f}-(\aleph-1) \varphi\left(\kappa_{f}-\kappa_{s}\right)}{\kappa_{s}+(1-\aleph) \kappa_{f}+\varphi\left(\kappa_{f}-\kappa_{s}\right)}\left(1+\alpha A_{2} T\right) .
\end{aligned}
$$

In equations (7) and (8), $m \geq 1$ is the shear-rate-viscosity parameter, $0 \leq n \leq 1$ is the shear-thinning parameter, and $\aleph$ is the empirical shape factor (where $\aleph=3$ for nanoparticles of spherical shape) [1]. The shear-rate viscosity parameter, $m$, gives the ratio of zero shear rate to the infinite shear-rate viscosities. The value $m=1$ indicates that the viscosity is independent of shear rates. This would be the case, say, for Newtonian fluids/nanofluids and for ordinary viscoelastic fluids/nanofluids. The generalized Newtonian-fluid-based nanofluid (GNFBN) model is obtained by taking $\beta=0($ and $m \neq 1)$ and $\mathrm{De}=0$. The choice $\mathrm{De}=\beta=0$ and $m=1$ represents a Newtonian nanofluid (refer to $[1,25]$ ).

2.1. Initial and Boundary Conditions. Given the symmetric flow geometry for the pressure-driven flow, it is sufficient to consider only the upper half channel $y \in[0,1]$ instead of the full channel $y \in[-1,1]$. The following initial and boundary conditions therefore apply:

$$
\begin{aligned}
u(0, y) & =0, T(0, y)=0, \tau(0, y)=0, \quad \text { for } 0 \leq y \leq 1, \\
\frac{\partial}{\partial y} u(t, 0) & =0, \frac{\partial}{\partial y} T(t, 0)=0, \quad \text { for } t>0 \\
u(t, 1) & =0, \frac{\partial}{\partial y} T(t, 1)=-\operatorname{Bi}\left[T(t, 1)-\theta_{a}\right], \quad \text { for } t>0 .
\end{aligned}
$$

\section{Numerical Solution}

The semi-implicit finite-difference numerical and computational methodologies are based on the ideas described in $[1,25]$. The velocity equation is discretized as

$$
\operatorname{Re}_{n f} \frac{u^{(n+1)}-u^{(n)}}{\Delta t}=\operatorname{Re}_{n f} G+\frac{\partial}{\partial y} \tau_{12}^{(n)}+\left(\left(\eta_{s}\right)_{n f}^{(n)} \frac{\partial^{2}}{\partial y^{2}} u^{(n+\xi)}+\frac{\partial}{\partial y} u^{(n)} \frac{\partial}{\partial y}\left(\eta_{s}\right)_{n f}^{(n)}\right),
$$

where $G=(\partial p / \partial x)=1$ denotes the constant pressure gradient in the flow direction. The velocity updates in time via the scheme 


$$
\begin{aligned}
-r_{1} u_{j-1}^{(n+1)}+\left(\operatorname{Re}_{n f}+2 r_{1}\right) u_{j}^{(n+1)}-r_{1} u_{j+1}^{(n+1)}= & \operatorname{Re}_{n f} u_{j}^{(n)}+\operatorname{Re}_{n f} G+(1-\xi) \Delta t\left(\eta_{s}\right)_{n f}^{(n)} \frac{\partial^{2}}{\partial y^{2}} u^{(n)} \\
& +\Delta t \frac{\partial}{\partial y} \tau_{12}^{(n)}+(1-\beta) \Delta t \frac{\partial}{\partial y} u^{(n)} \frac{\partial}{\partial y}\left(\eta_{s}\right)_{n f}^{(n)}
\end{aligned}
$$

where

$$
r_{1}=\xi\left(\eta_{s}\right)_{n f}^{(n)} \frac{\Delta t}{\Delta y^{2}}
$$

The resultant system of algebraic equations represents a diagonally dominant tridiagonal linear system. The semiimplicit finite-difference method for temperature equation follows similarly:

$$
\mathrm{Pe}_{n f} \frac{\partial T}{\partial t}=\kappa_{n f}^{(n)} \frac{\partial^{2}}{\partial y^{2}} T^{(n+\xi)}+\frac{\partial}{\partial y} T^{(n)} \frac{\partial}{\partial y} \kappa_{n f}^{(n)}+\operatorname{BrQ}_{D}^{(n)}+\delta_{1} \exp \left(\frac{T^{(n)}}{1+\alpha T^{(n)}}\right)
$$

Specifically, the temperature updates in time via the scheme

$$
\begin{aligned}
-r_{2} T_{j-1}^{(n+1)}+\left(P e_{n f}+2 r_{2}\right) T_{j}^{(n+1)}-r_{2} T_{j+1}^{(n+1)}= & \operatorname{Pe}_{n f} T_{j}^{(n)}+(1-\xi) \Delta t \kappa_{n f} \frac{\partial^{2}}{\partial y^{2}} T^{(n)} \\
& +\Delta t \frac{\partial}{\partial y} T^{(n)} \frac{\partial}{\partial y} \kappa_{n f}^{(n)}+\Delta t \operatorname{Br}\left(\eta_{s}\right)_{n f}^{(n)}\left(\frac{\partial}{\partial y} u^{(n)}\right)^{2}+\delta_{1} \exp \left(\frac{T^{(n)}}{1+\alpha T^{(n)}}\right) \\
& +\Delta t \operatorname{Br} \gamma \tau_{12}^{(n)} \frac{\partial}{\partial y} u^{(n)}+(1-\gamma) \Delta t B r \frac{\widehat{G}}{2 \operatorname{De} \bar{\lambda}(T)}\left(I_{1}+\operatorname{Tr}\left(b^{-1}\right)-6\right)
\end{aligned}
$$

where

$$
r_{2}=\xi \kappa_{n f} \frac{\Delta t}{\Delta y^{2}}
$$

The equations for the extra stress tensor, $\tau$ (3), are solved analogously:

$\tau^{(n+\xi)}+\varepsilon\left(\tau^{2}\right)^{(n)}+\operatorname{De} \bar{\lambda}^{(n)} \frac{\tau^{(n+1)}-\tau^{(n)}}{\Delta t}=$ explicit terms.

$$
\begin{aligned}
& {\left[\operatorname{De} \bar{\lambda}^{(n)}-(1-\xi) \Delta t\right] \tau_{11}^{(n)}+\Delta t \operatorname{De} \bar{\lambda}^{(n)}\left[\tau_{12}^{(n)} \frac{\partial}{\partial y} u^{(n)}+\tau_{11}^{(n)} \frac{\partial}{\partial y} \log \left(1+\alpha T^{(n)}\right)\right]-\varepsilon \Delta t\left(\tau_{11}^{2}+\tau_{12}^{2}\right)} \\
& {\left[\operatorname{De} \bar{\lambda}^{(n)}-(1-\xi) \Delta t\right] \tau_{12}^{(n)}+\Delta t \operatorname{De} \bar{\lambda}^{(n)}\left[\tau_{22}^{(n)} \frac{\partial}{\partial y} u^{(n)}+\tau_{12}^{(n)} \frac{\partial}{\partial y} \log \left(1+\alpha T^{(n)}\right)\right]+\Delta t\left(\eta_{p}\right)_{n f} \frac{\partial}{\partial y} u^{(n)}-\varepsilon \Delta t\left(\tau_{11} \tau_{12}+\tau_{22}^{2}\right)} \\
& {\left[\operatorname{De} \bar{\lambda}^{(n)}-(1-\xi) \Delta t\right] \tau_{22}^{(n)}+\Delta t \operatorname{De} \bar{\lambda}^{(n)} \tau_{22}^{(n)} \frac{\partial}{\partial y} \log \left(1+\alpha T^{(n)}\right)-\varepsilon \Delta t\left(\tau_{12}^{2}+\tau-12 \tau_{22}\right)}
\end{aligned}
$$




\section{Results}

Unless otherwise indicated, the following list of values, for the embedded variables and material parameters, will be assumed:

$$
\begin{aligned}
\alpha & =0.1, \mathrm{Br}=1, \mathrm{Re}=1, \operatorname{Pr}=1, \mathrm{De}=2, \gamma=0.5, \beta=0.2, \Delta y=0.01, \\
\Delta t & =0.1, t=50, \widehat{G}=10^{-3}, m=1.2, \delta_{1}=0.1, \lambda=0.01, n=0.5, \zeta=1, \\
\varphi & =0.04, \varepsilon=0, A_{2}=0.2, \mathrm{Bi}=1, \theta_{a}=0.1, \aleph=3
\end{aligned}
$$

The above will constitute the default variable and parameter values in this study. In the subsequent graphical results, it will be assumed and understood that, where variable and parameter values are not explicitly stated, they will be given by the default values.

4.1. Convergence in Time and Space. It is important to validate the utility of a numerical and computational algorithm before deploying it to solving physical problems. Figures 2-5 show, as required, that the computational algorithms are independent of both time step and mesh size-specifically, the algorithms give the same results for a large range of time steps and mesh sizes.

4.2. Transient Development of Solutions to Steady State. Given the focus on unsteady flow, it is equally important (in addition to the demonstration of time step and mesh size convergence) to demonstrate that the algorithms are capable of capturing the transient (time) development of steady solutions, including the capabilities to also illustrate the final steady-state solutions. Figures 6 and 7 show, as required, the development of solutions in time until steady states are reached.

4.3. Parameter Dependence of Solutions. Figure 8 gives an illustration of the variation of flow quantities with $\varphi$, the volume fraction of the embedded nanoparticles. The results show an increase in the flow quantities with increasing $\varphi$. The increase in fluid temperature with increasing $\varphi$ is obvious, given that the increased volume of heat conducting nanoparticles would directly also increase fluid thermal conductivity (see Figure 9).

The increase in fluid temperature naturally also decreases the fluid viscosity and hence also diminishes the viscous drag effects, hence the increase in fluid velocity with increasing $\varphi$ as observed in Figure 8.

Viscous effects are inversely proportional to the Reynolds number, Re. Alternatively, high speed flows are synonymous with high Reynolds numbers. Figure 10 therefore demonstrates, as expected, an increase in velocity with increasing Re. Figure 11 shows the dependence of flow quantities with Brinkman number, $\mathrm{Br}$. Since $\mathrm{Br}$ is directly connected to the strength of the heat sources, the fluid temperature (and hence also the fluid velocity) is expected to increase with increasing $\mathrm{Br}$ as illustrated in Figure 11. The polymeric-stress component $\tau_{11}$, on the other hand, decreases with increasing $\mathrm{Br}$.

Given their opposing influence to heat sources in the energy equation, the fluid temperature behaves oppositely with increasing Prandtl number Pr (see Figure 12), as it would with Br.

The Prandtl number indirectly enters the momentum and polymeric-stress equations via the temperature dependence of the viscosity. For these reasons, small variations in Pr have no discernible influence on the fluid velocity and polymeric-stress components (Figure 12). The activationenergy parameter, $\alpha$, has similar effects to those of $\mathrm{Br}$ (see Figure 13). The increase of fluid temperature with increasing $\alpha$ as illustrated in Figure 13 can be directly linked to the increase of nanofluid thermal conductivity, $\kappa_{n f}$, with increasing $\alpha$ (see Figure 14).

Figure 15 illustrates the required increase in fluid velocity with increased pressure driving force.

The behaviour of fluid temperature with variations in the exothermic-reaction parameter $\delta_{1}$ is similar to that with respect to $\mathrm{Br}$ given the linkages of these parameters to the heat sources (see Figure 16). The major difference is that the fluid temperature increases linearly with increasing $\mathrm{Br}$, whereas the fluid temperature increases exponentially with increasing $\delta_{1}$ (see [25]). The possibility of thermal runway phenomena therefore looms large with regard to increases in $\delta_{1}$ due to exponential temperature growth. Indeed, for large values of the exothermic-reaction parameter $\delta_{1}$, the steadystate solutions would not be attainable-the solutions would blow up in finite time (see Figure 17).

The respective behaviour of flow quantities with variations in the viscoelastic parameters, $\gamma$ and De, is illustrated in Figures 18 and 19, respectively.

As expected, the polymeric (viscoelastic) stresses increase with increasing De. It is also noticed, as expected, that the fluid temperature increases with increasing $\gamma$ given the dominance of entropic heat dissipation (over energetic heat storage) for larger values of $\gamma$.

The heat exchange between the ambient environment, the channels walls, and the nanofluid is related to the Biot number Bi (see (10)). Enhanced convective cooling at the channel walls is directly related to higher $\mathrm{Bi}$. The cooled walls in turn lead to lower nanofluid temperatures in the bulk flow. Figure 20 therefore illustrates, as expected, the decrease in (bulk) nanofluid temperature with increasing Bi. 


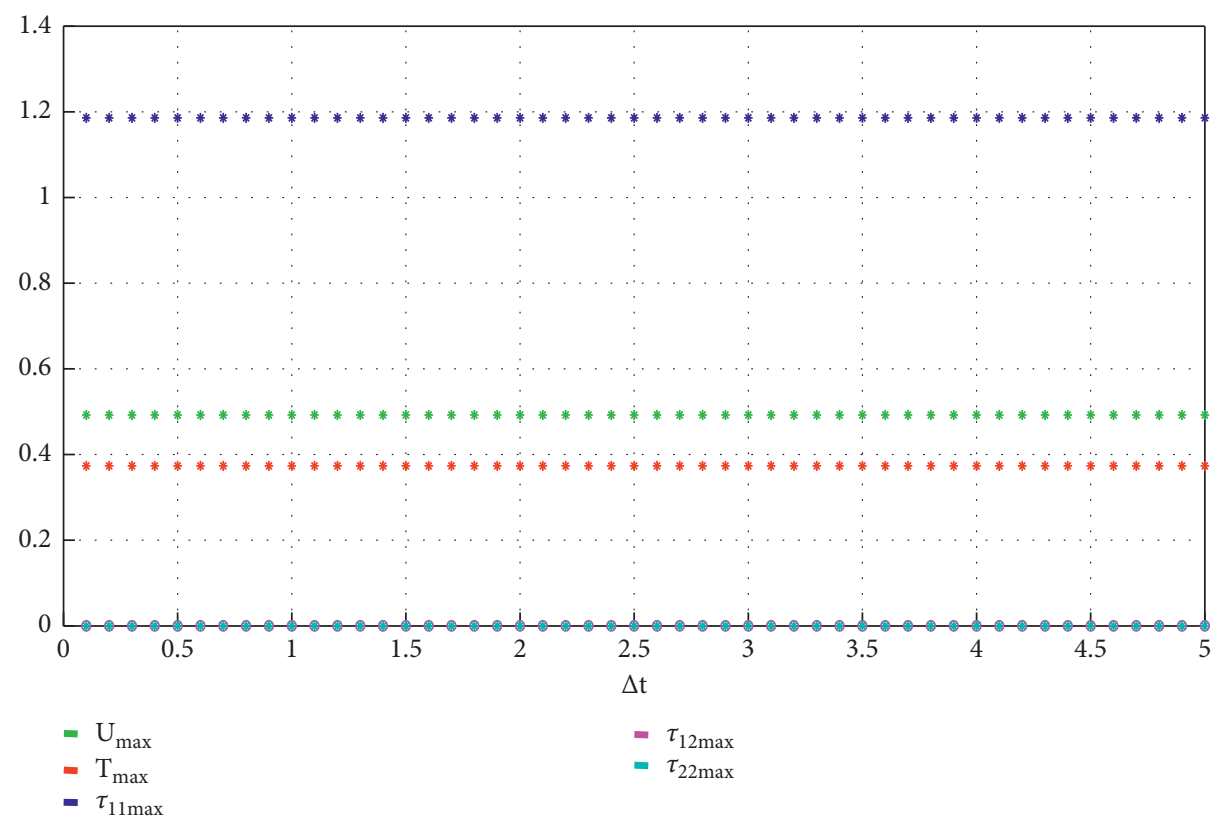

FIgUre 2: Dependence of solutions on time step size.

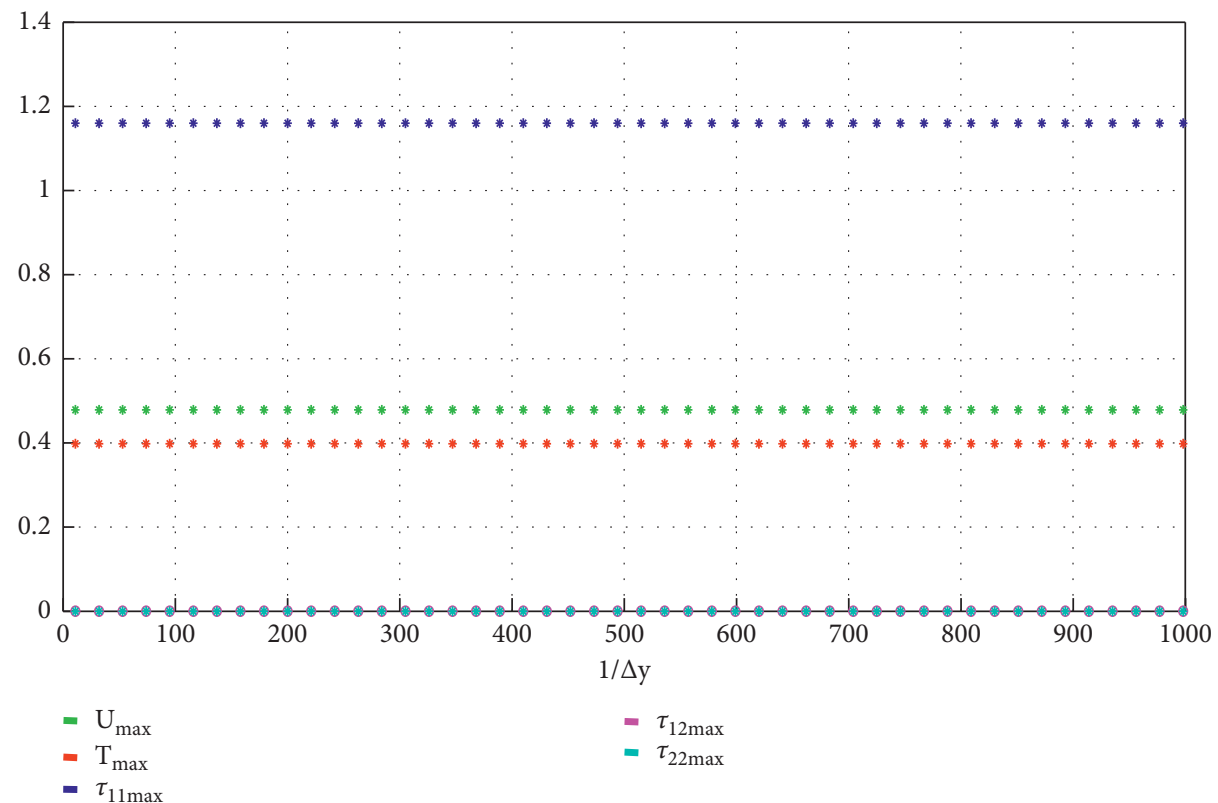

Figure 3: Dependence of solutions on mesh size.

The nanofluid viscosity (at constant shear rates) increases with increasing shear-thinning parameter, $m$. An increase in $m$ therefore increases resistance to flow (due to the higher viscosity) and hence leads to a decrease in fluid velocity as shown in Figure 21. A decrease in both the fluid temperature and the polymeric stresses with increasing $m$ is also noticed. 

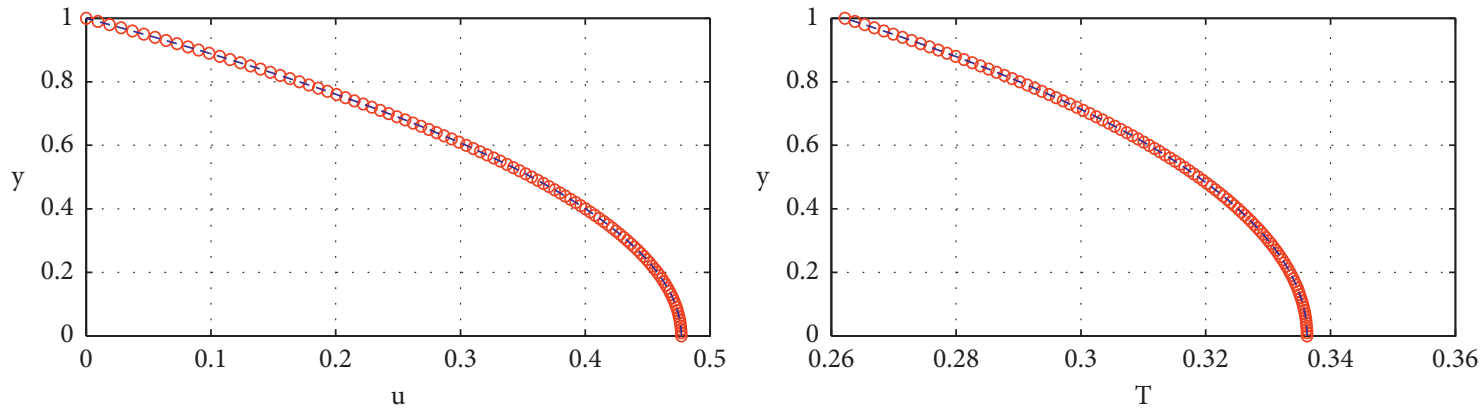

ㅇ $\Delta \mathrm{t}=0.01$

ㅇ $\Delta \mathrm{t}=0.01$

$--\Delta \mathrm{t}=3$

$--\Delta \mathrm{t}=3$
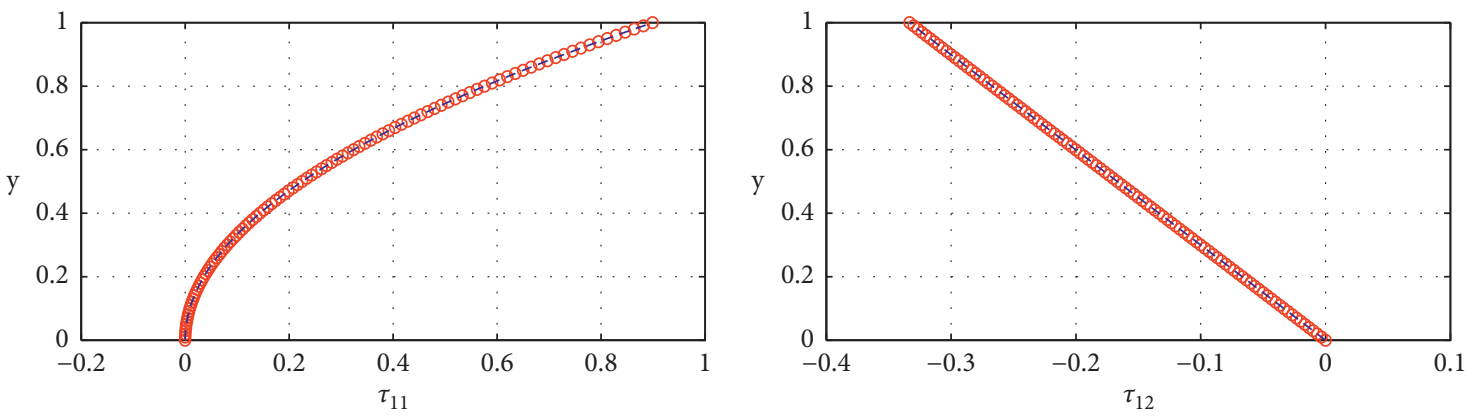

○ $\Delta \mathrm{t}=0.01$

○ $\Delta \mathrm{t}=0.01$

$--\Delta \mathrm{t}=3$

$--\Delta \mathrm{t}=3$

FIgURE 4: Dependence of solutions on time step size.
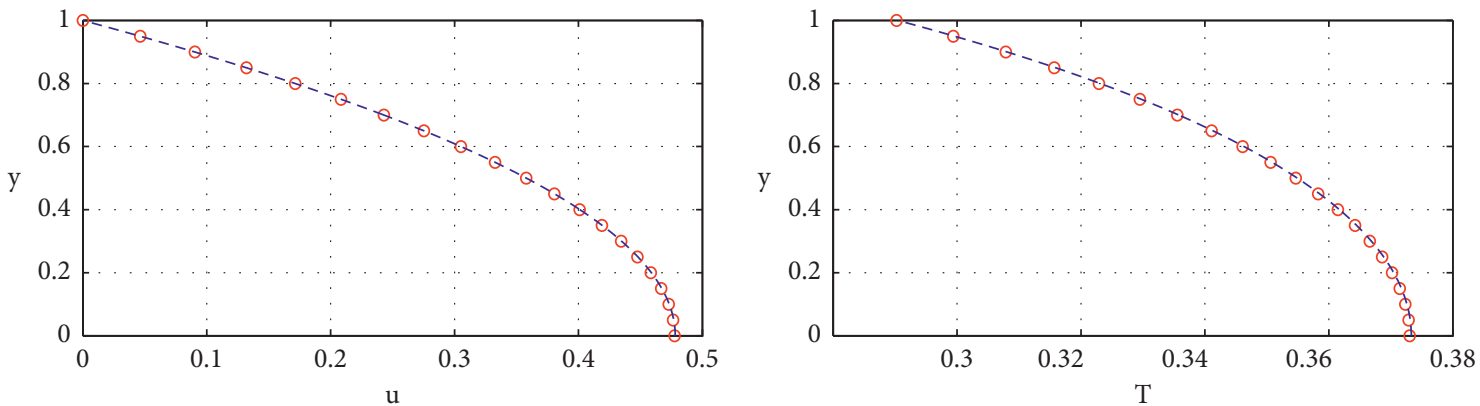

- $1 / \Delta \mathrm{y}=20$

$---1 / \Delta \mathrm{y}=1000$

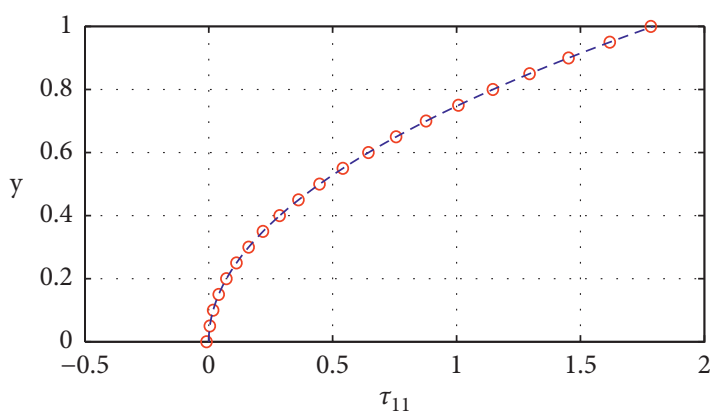

- $1 / \Delta \mathrm{y}=20$

$--1 / \Delta y=1000$

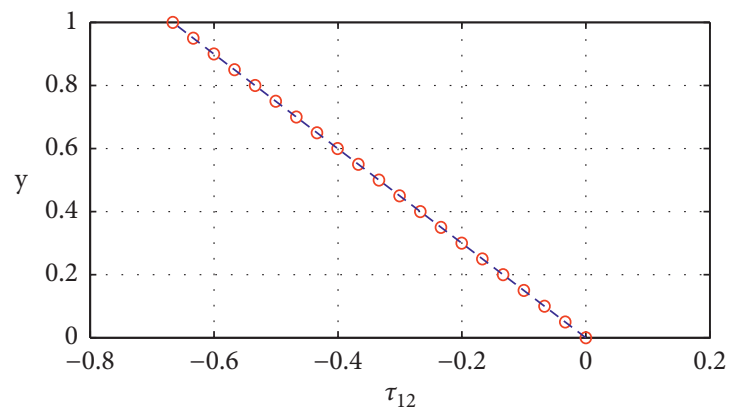

- $1 / \Delta \mathrm{y}=20$

- $1 / \Delta y=20$

$---1 / \Delta y=1000$

- - $1 / \Delta \mathrm{y}=1000$

Figure 5: Dependence of solutions on mesh size. 

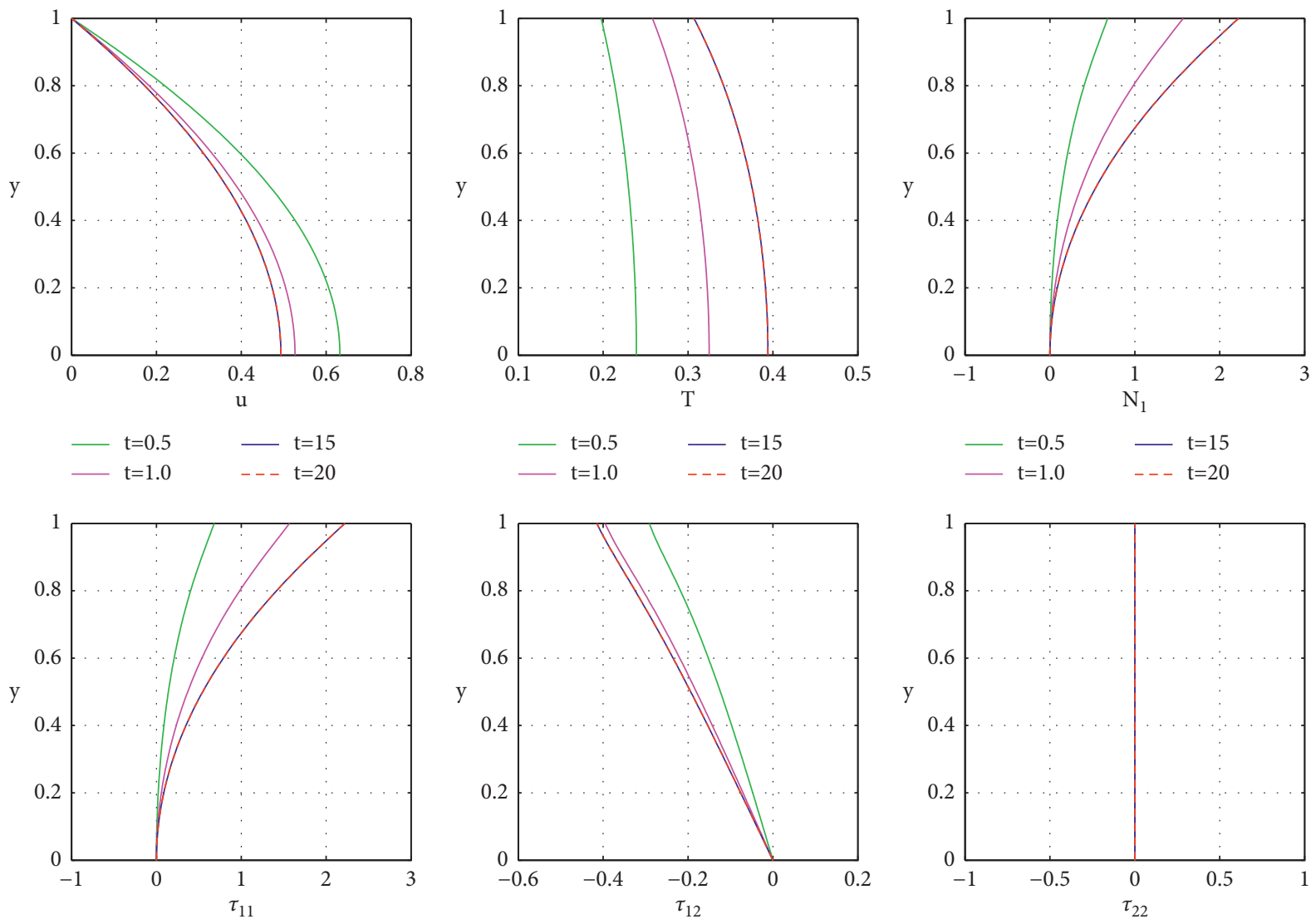

$\begin{aligned} \mathrm{t}=0.5 & -\mathrm{t}=15 \\ \mathrm{t}=1.0 & --\mathrm{t}=20\end{aligned}$

$-\begin{aligned} \mathrm{t}=0.5 & -\mathrm{t}=15 \\ \mathrm{t}=1.0 & ---\mathrm{t}=20\end{aligned}$

$\begin{aligned} \mathrm{t}=0.5 & -\mathrm{t}=15 \\ \mathrm{t}=1.0 & --\mathrm{t}=20\end{aligned}$

Figure 6: Transient development to steady-state profiles, $\Delta t=0.05$.

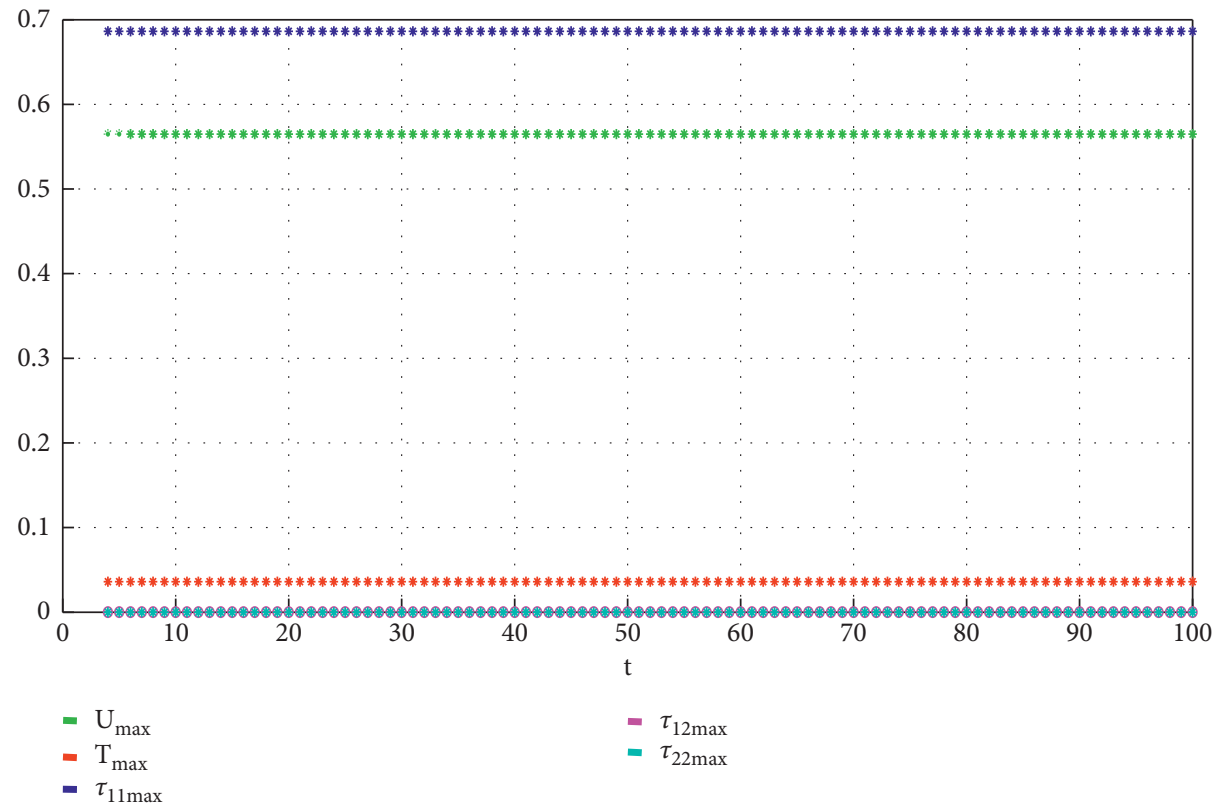

Figure 7: Transient development of steady maximum flow quantities. 

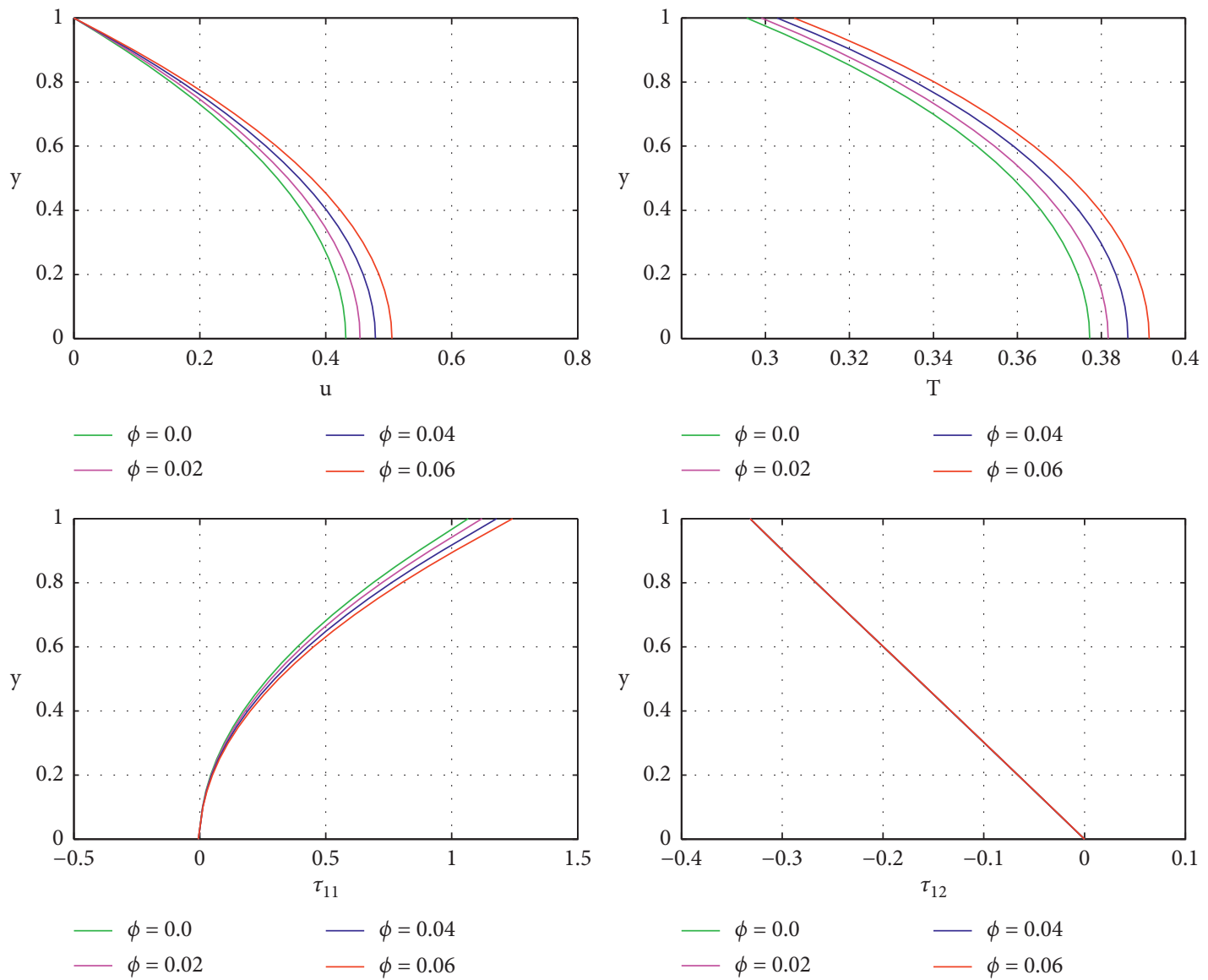

$-\phi=0.04$

$\begin{aligned}-\phi & =0.0 & -\phi & =0.04 \\ & =0.02 & -\phi & =0.06\end{aligned}$

FIGURE 8: Response of flow quantities to variations in $\varphi$.

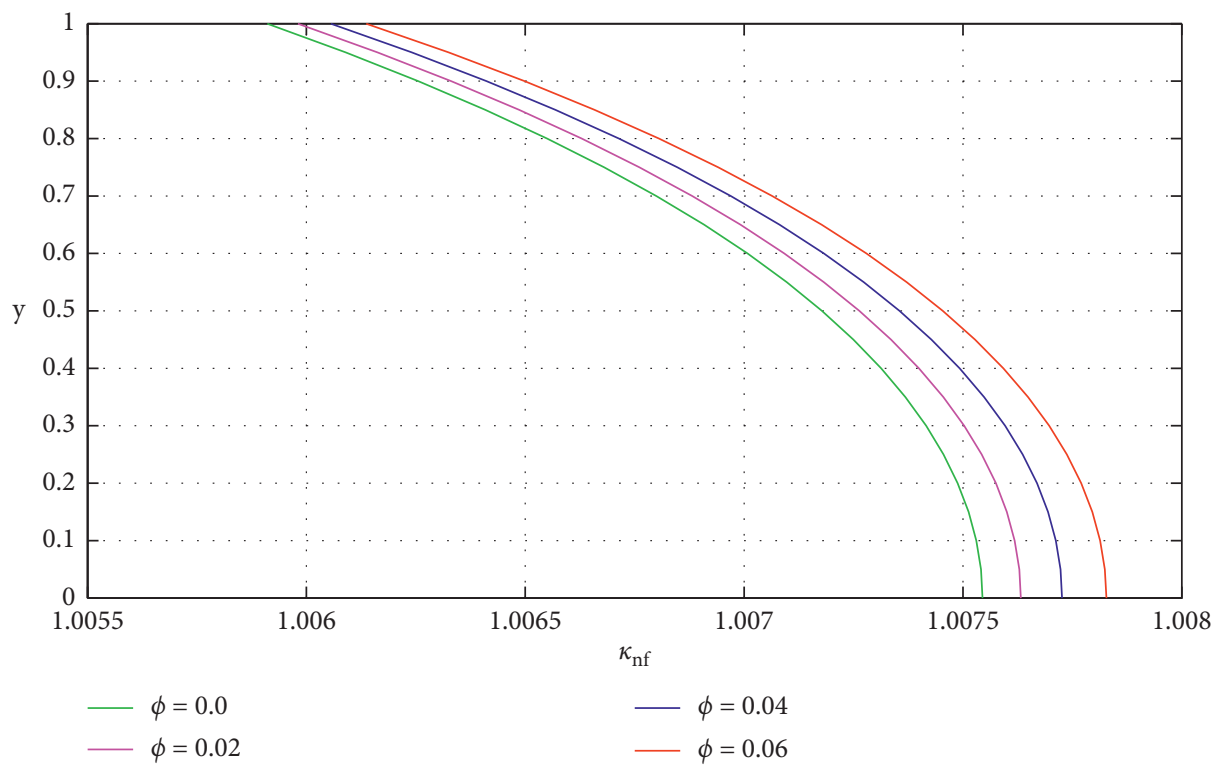

FIgURE 9: Response of nanofluid thermal conductivity to variations in $\varphi$. 

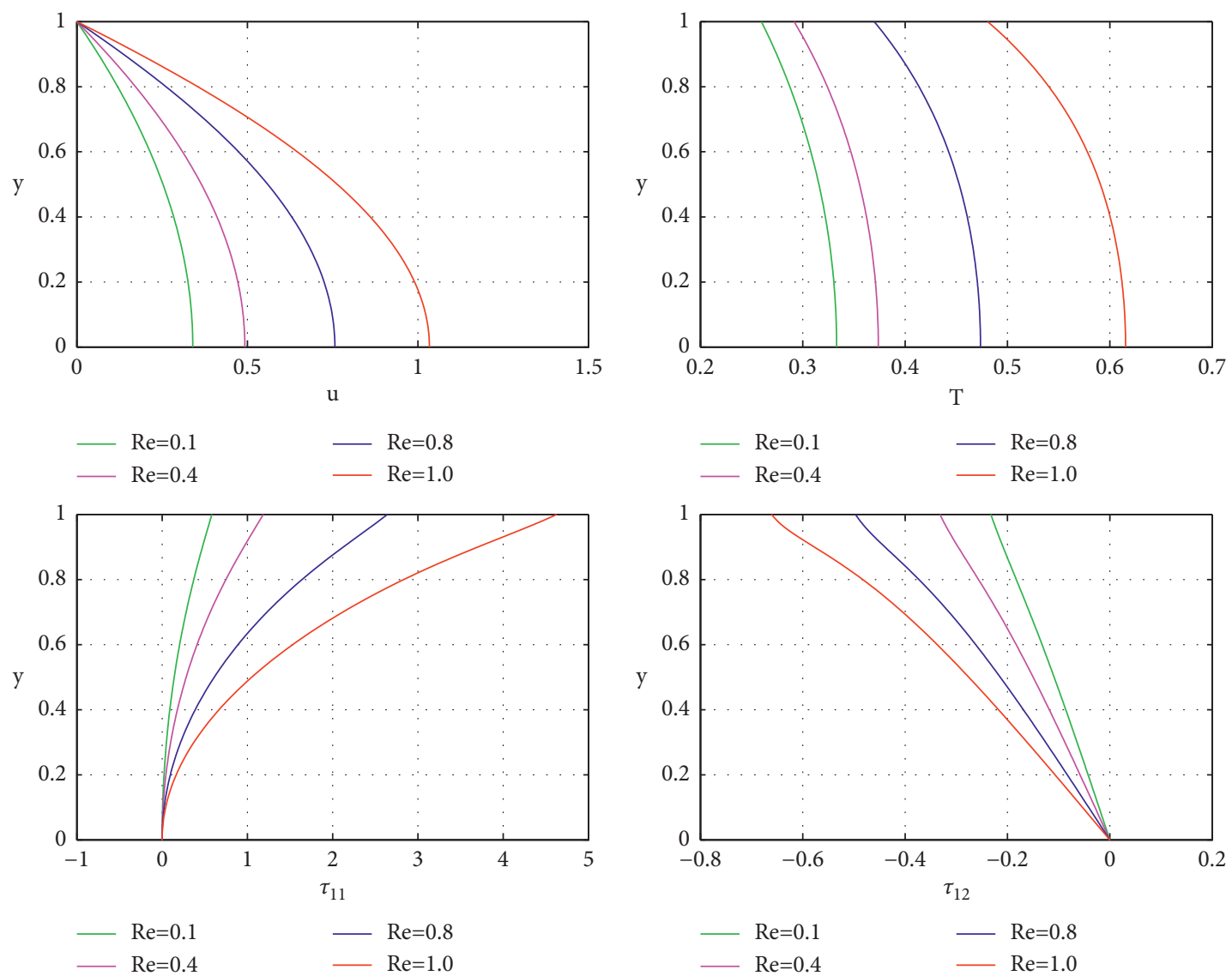

FIgURE 10: Response of flow quantities to variations in Re.
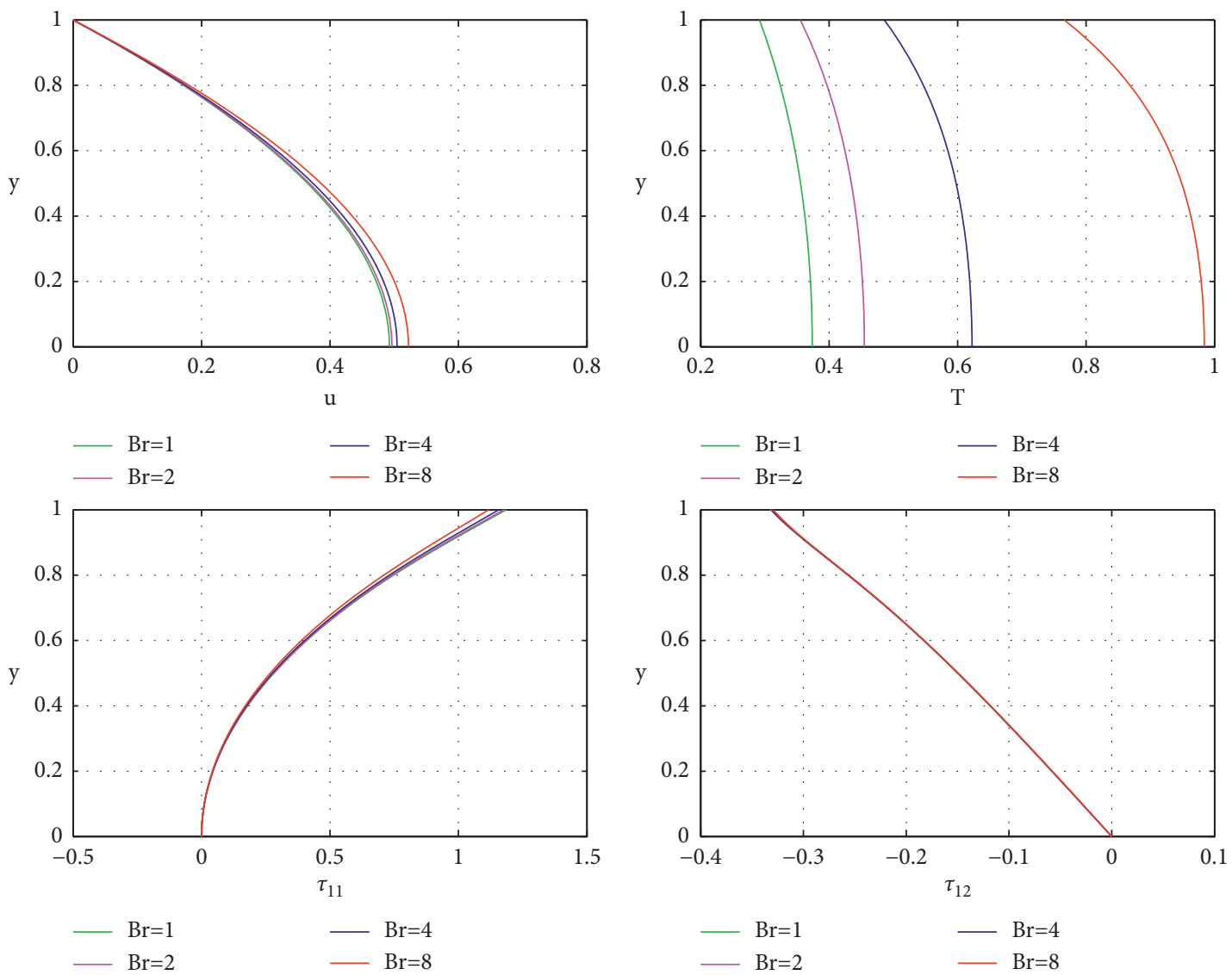

FIgURE 11: Response of flow quantities to variations in $\mathrm{Br}$. 

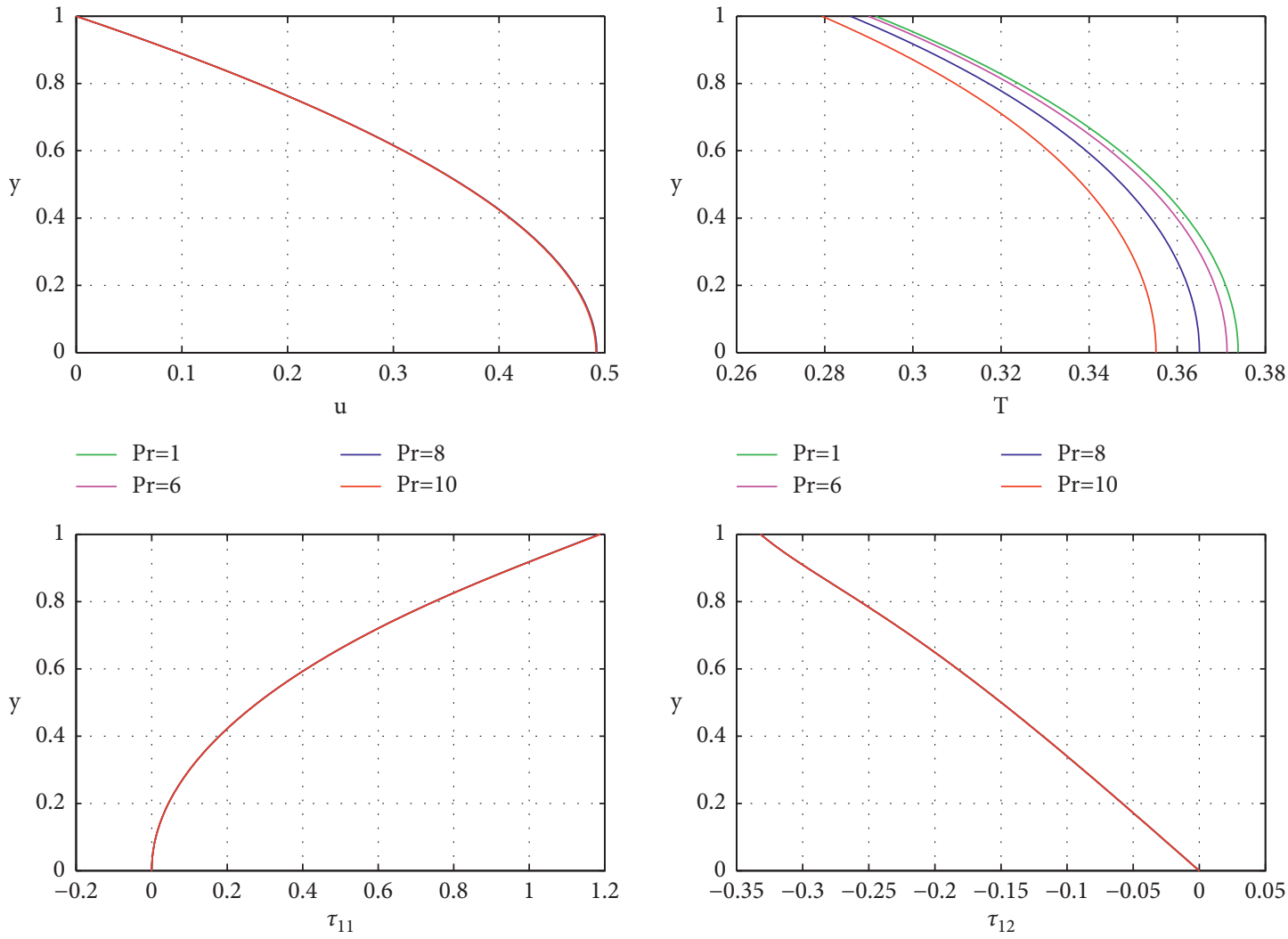

$\operatorname{Pr}=1$
$-\operatorname{Pr}=6$

- $\operatorname{Pr}=8$

$\operatorname{Pr}=1$
$-\operatorname{Pr}=6$

$\operatorname{Pr}=8$
$-\operatorname{Pr}=10$

Figure 12: Response of flow quantities to variations in $\mathrm{Pr}$.
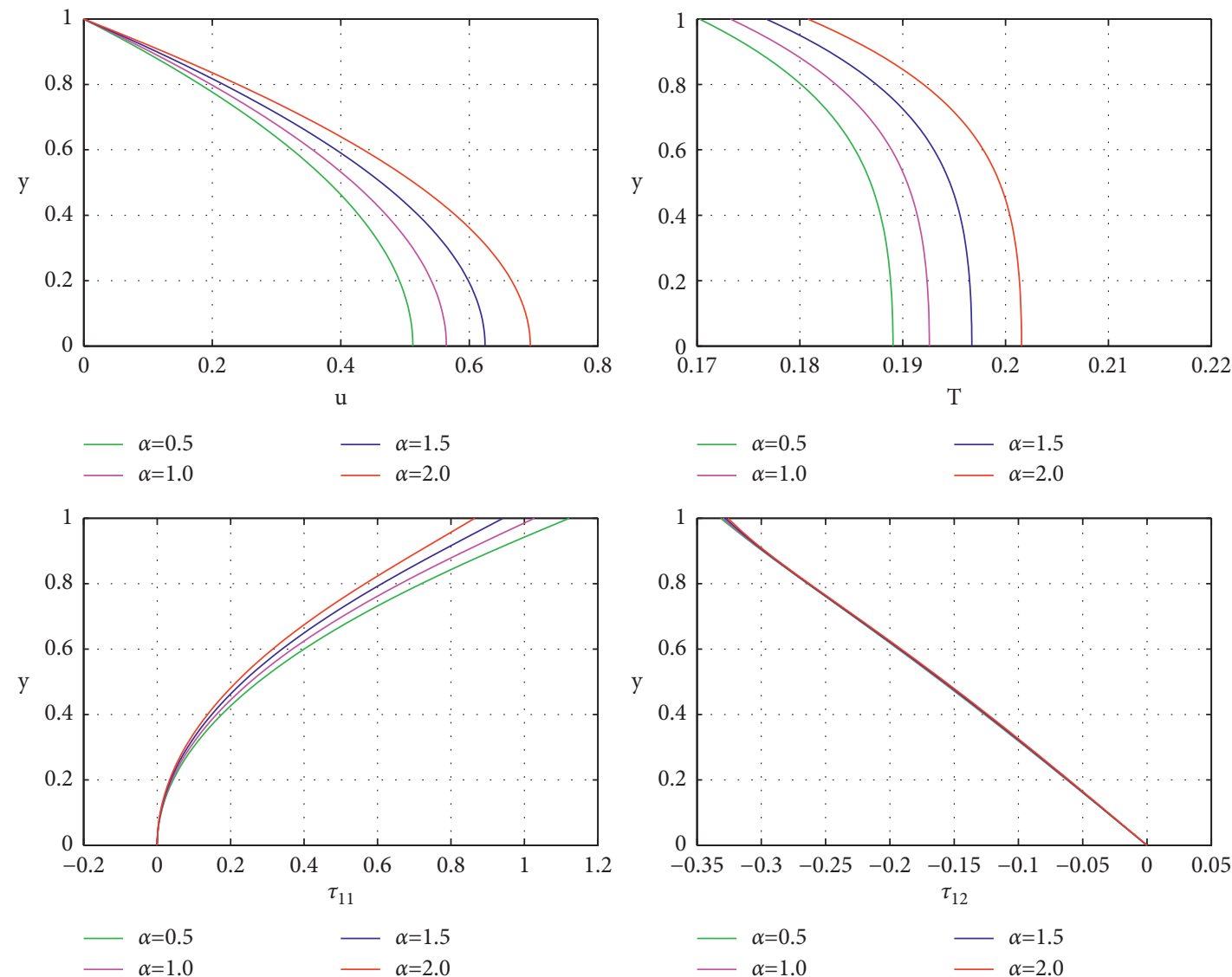

FIgURE 13: Response of flow quantities to variations in $\alpha$, where $\delta_{1}=0.001$. 


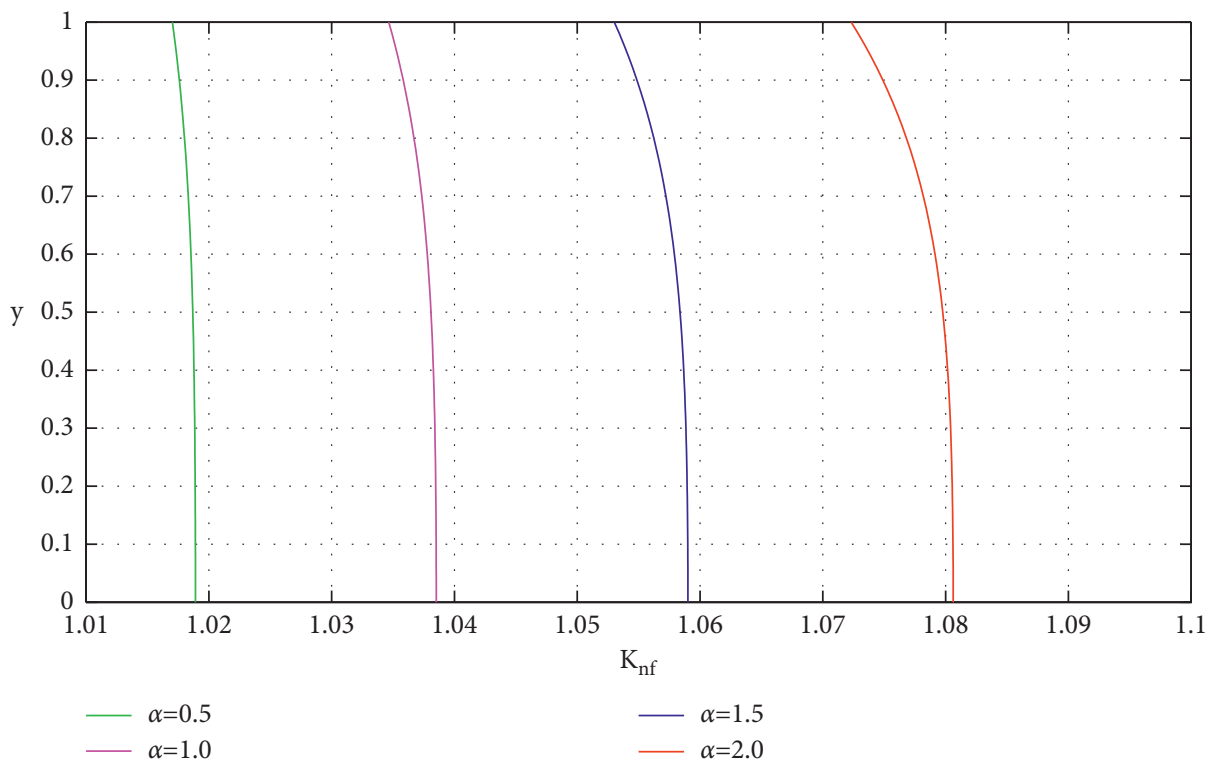

FIGURE 14: Response of nanofluid thermal conductivity, $\kappa_{n f}$, to variations in $\alpha$.

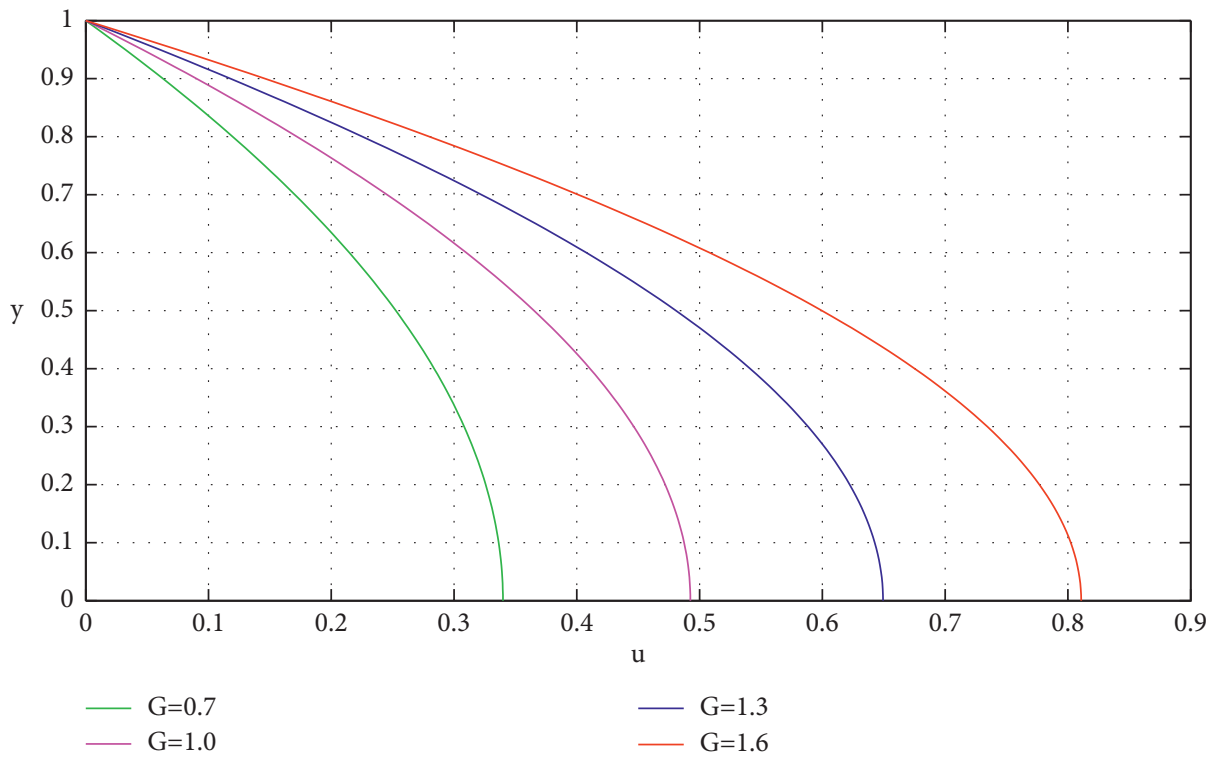

FIGURE 15: Effects of variations in pressure driving force on fluid velocity. 

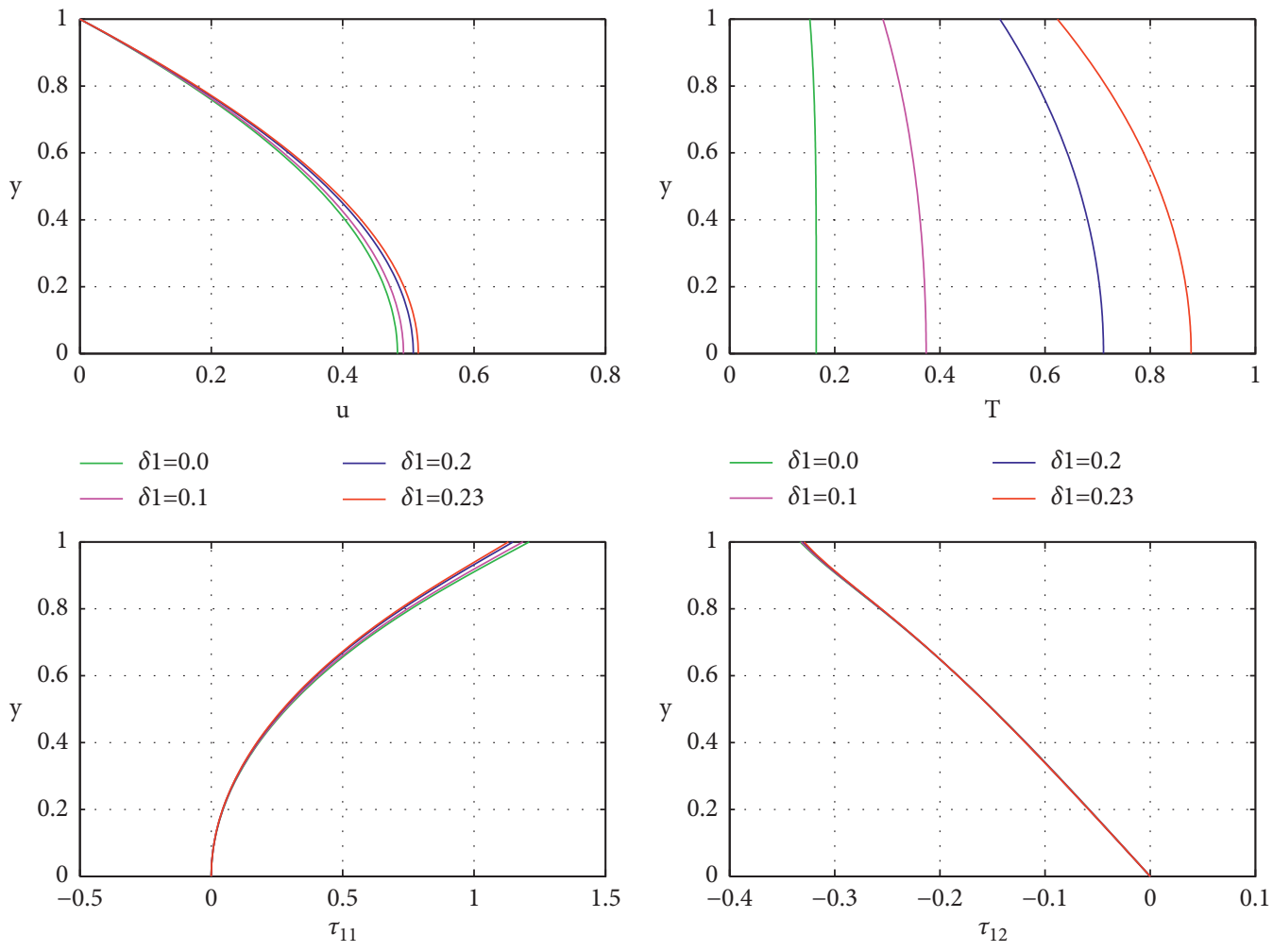
$-\delta 1=0.0$
$-\delta 1=0.2$
$-\delta 1=0.1$
$\delta 1=0.23$
$-\delta 1=0.0$
$-\delta 1=0.2$
$\delta 1=0.1$
$-\delta 1=0.23$

FIgURE 16: Response of flow quantities to variations in $\delta_{1}$.

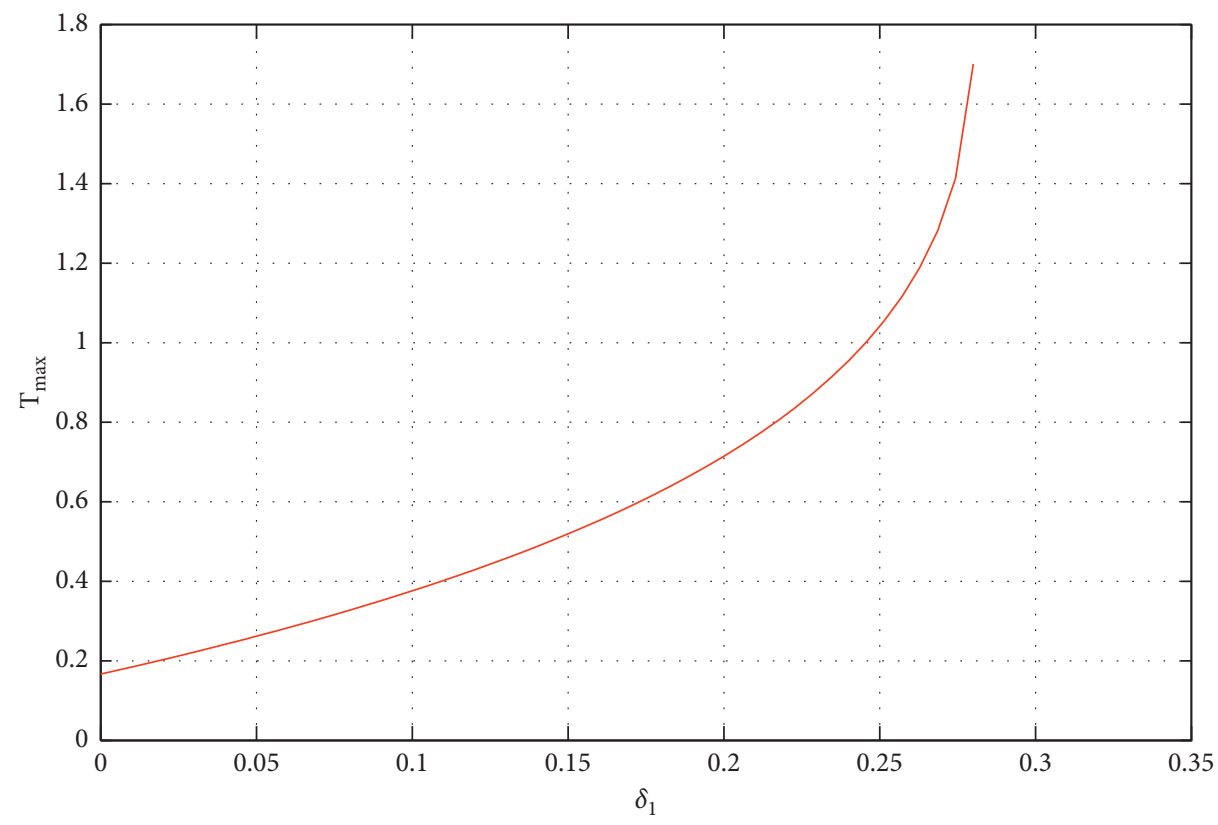

Figure 17: Finite time blow-up of fluid temperature for large value of $\delta_{1}$. 

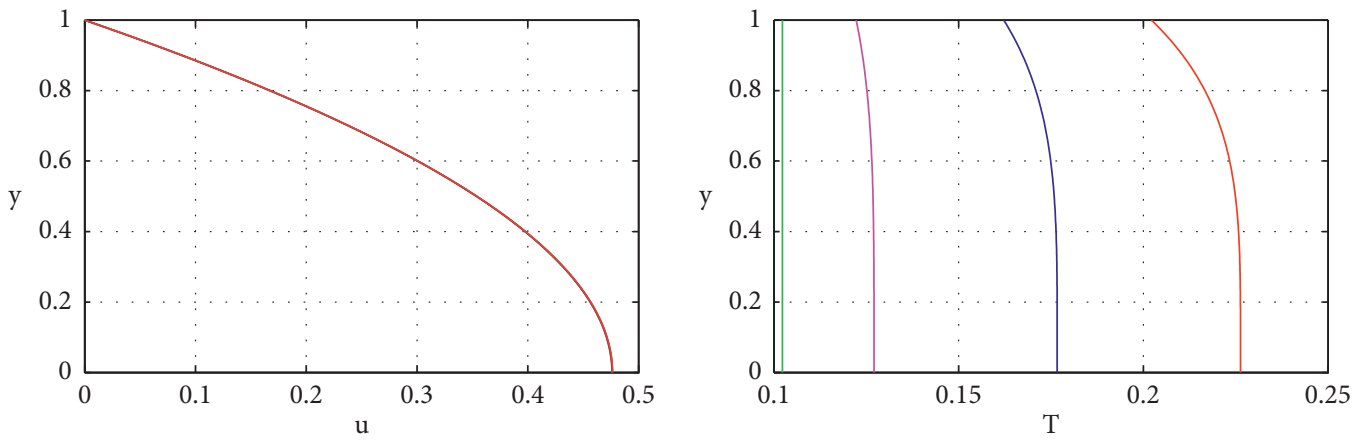

$\begin{array}{ll}\gamma=0.0 \\ \gamma=0.4 & -\gamma=0.8 \\ -\gamma=1.0\end{array}$
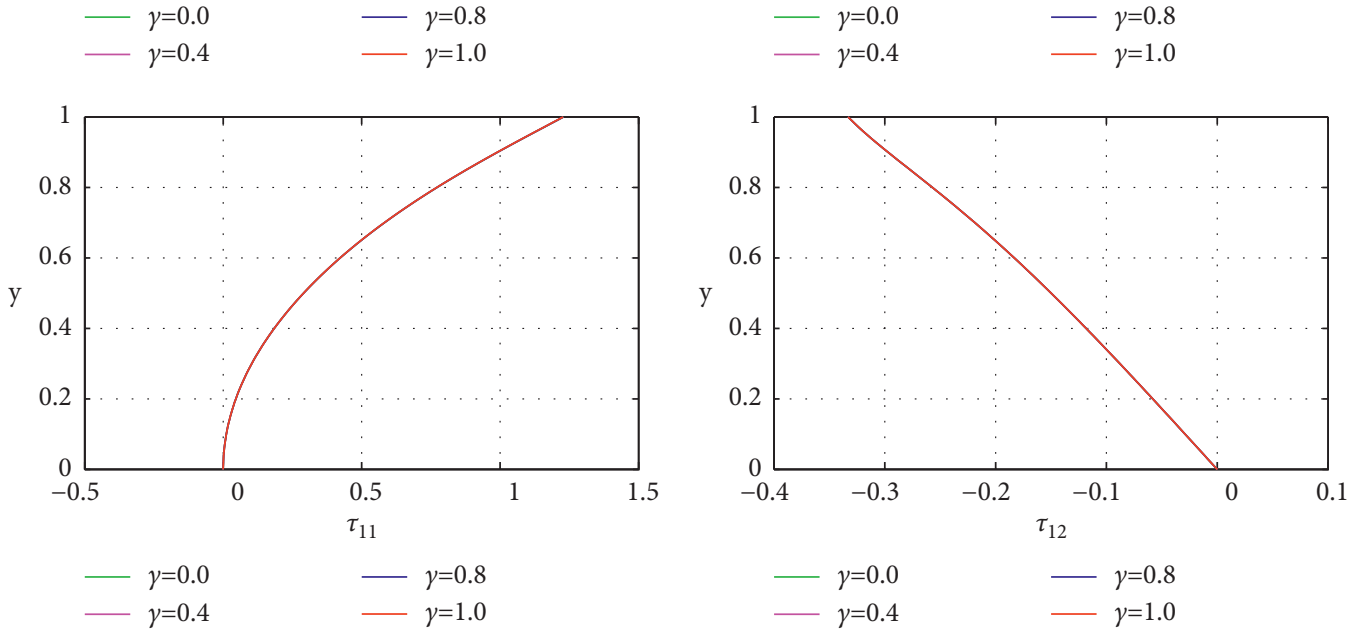

- $\gamma=0.8$

— $\gamma=0.0$

- $\gamma=0.8$

Figure 18: Response of flow quantities to variations in $\gamma$.
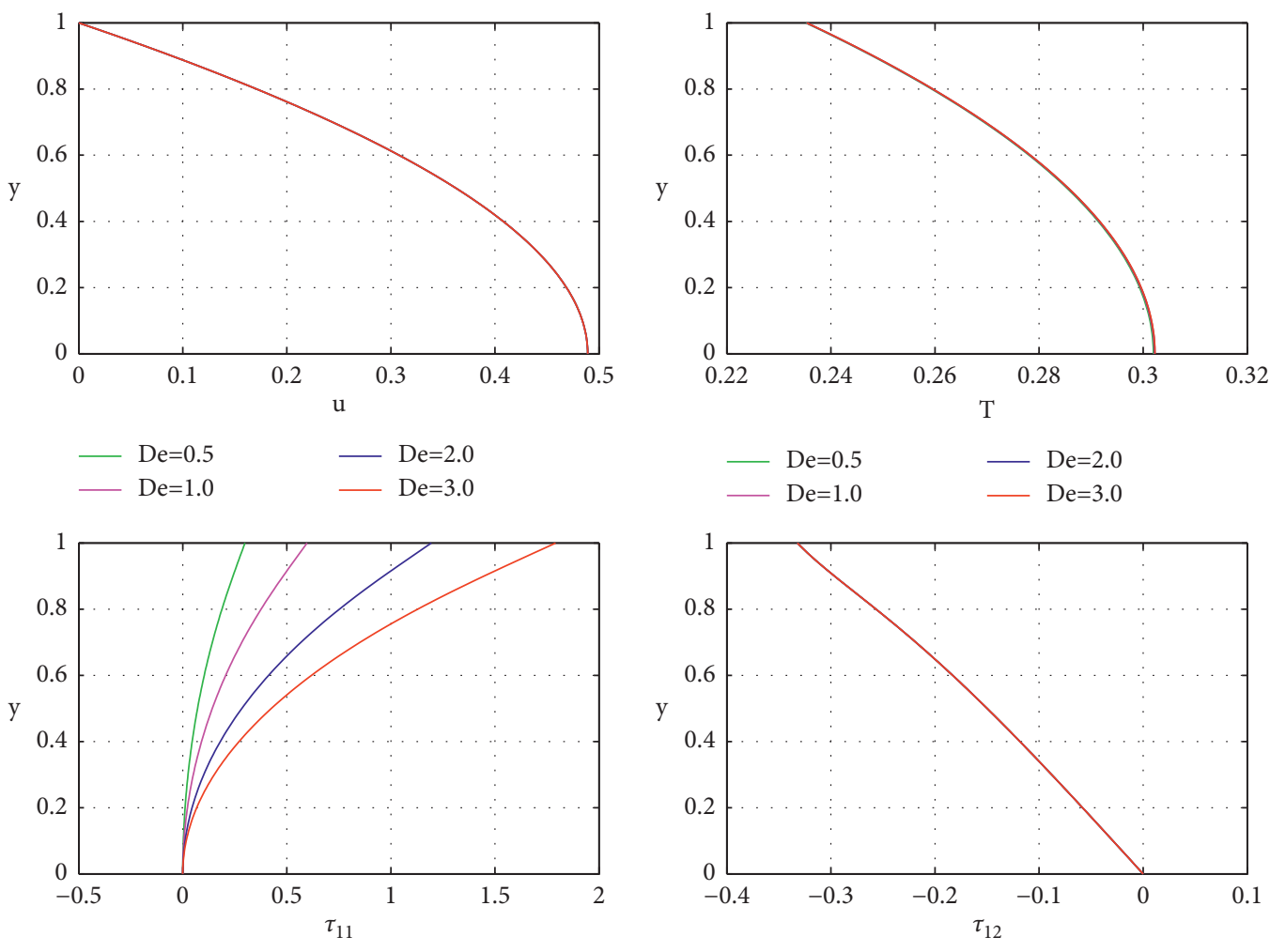

$\mathrm{De}=0.5$
$\mathrm{De}=1.0$

- De $=2.0$

- $\mathrm{De}=0.5$

— $\mathrm{De}=2.0$

- $\mathrm{De}=1.0$

$\mathrm{De}=3.0$

FIgURE 19: Response of flow quantities to variations in De. 

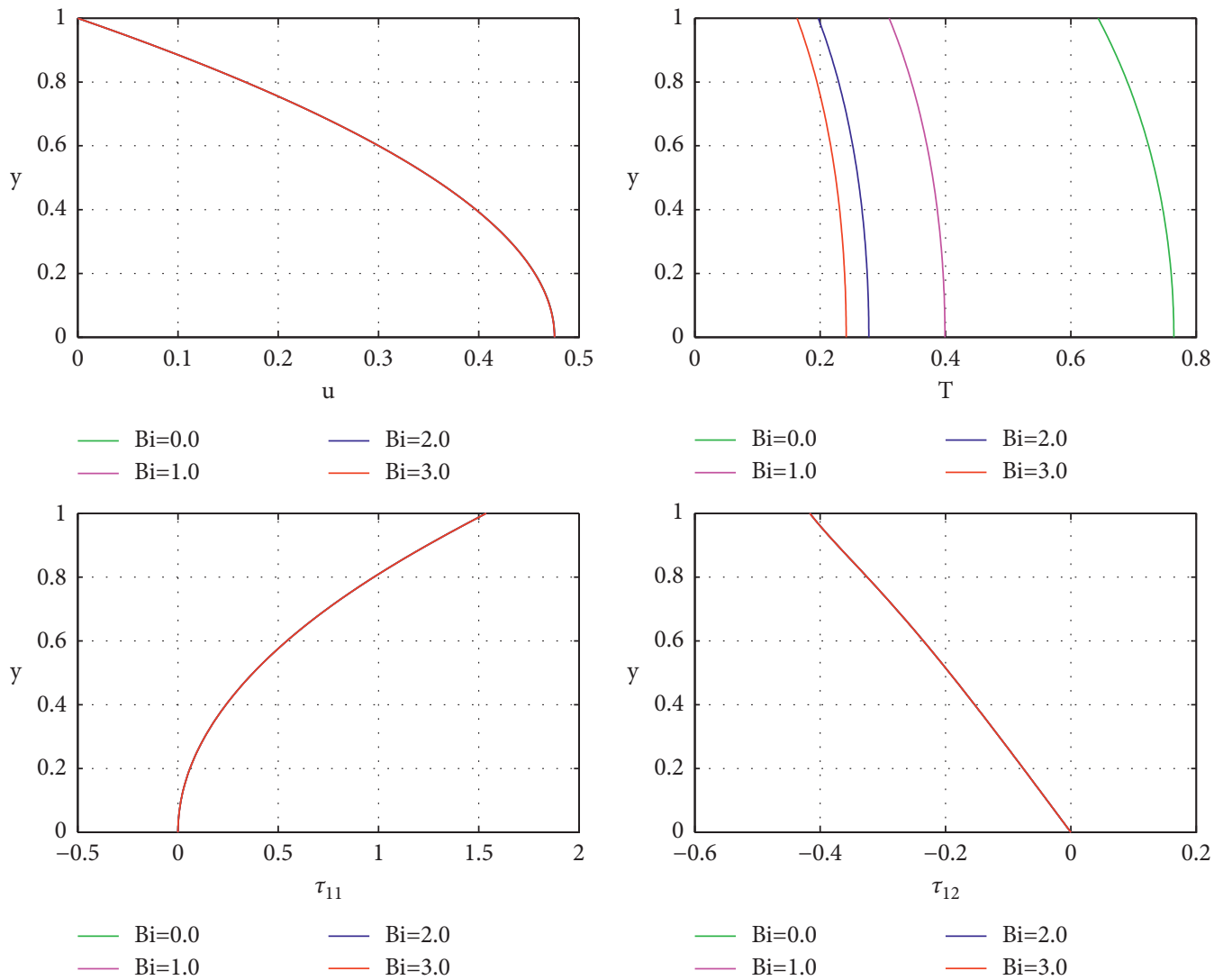

$-\mathrm{Bi}=2.0$

$-\mathrm{Bi}=3.0$

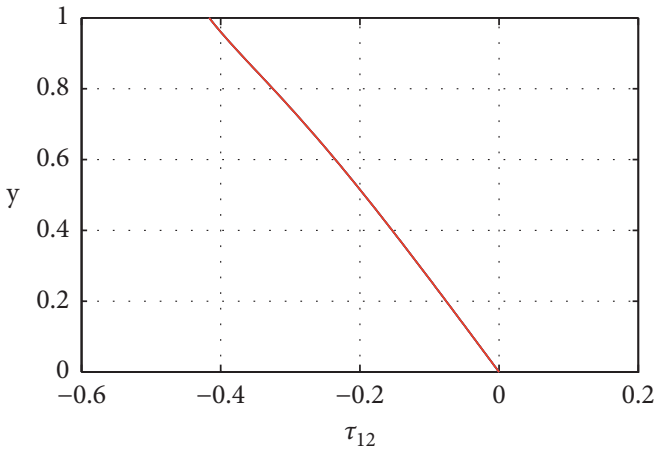

FIgURE 20: Response of flow quantities to variations in $\mathrm{Bi}$.
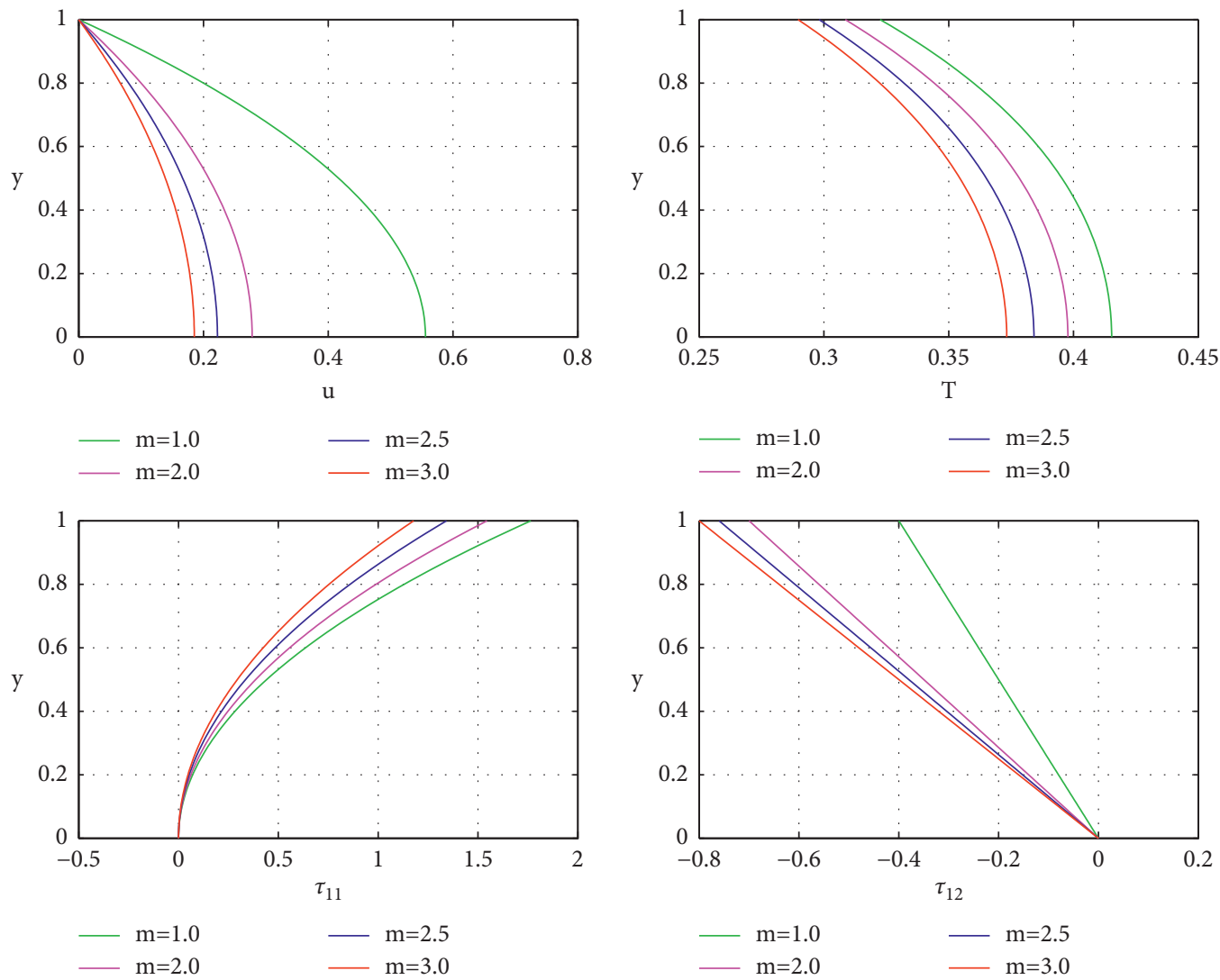

FIgURE 21: Response of flow quantities to variations in $m$. 


\section{Concluding Remarks}

The investigation employed efficient and convergent semiimplicit numerical and computational algorithms based on the finite-difference methods to analyze the non-isothermal, pressure-driven, channel flow of a generalized viscoelasticfluid-based nanofluid (GVFBN) subject to convective cooling at the channel boundaries. The assumed mathematical model is based on a single-phase (constant concentration) nanofluid mixture in which the nanoparticles are homogeneously mixed with the generalized viscoelastic-fluid base. The research results are explored in qualitative (graphical) detail illustrating the effects of the variations of the fundamental embedded parameters on the flow quantities, specifically, the fluid velocity, fluid temperature, and polymer stresses. The results demonstrate that those parameters which only directly couple to the energy equation (but are otherwise indirectly coupled to the momentum and stress-constitutive equations, say via the viscosities and relaxation times) would only show prominent effects on nanofluid temperature but not on the fluid velocity or the polymer stresses. The results also demonstrate, as in the literature on exothermic flows, that the values of exothermic-reaction parameter must be carefully controlled as large values would lead to thermal runway phenomena. The present results are consistent with the existing literature and additionally add novel new contributions to non-isothermal and pressure-driven channel flow of GVFBN under convective cooling conditions.

\section{Data Availability}

The data used to support the findings of this study are available from the corresponding author upon request.

\section{Conflicts of Interest}

The authors declare that they have no conflicts of interest.

\section{References}

[1] I. Khan, T. Chinyoka, and A. Gill, "Computational analysis of the dynamics of generalized-viscoelastic-fluid-based nanofluids subject to exothermic-reaction in shear-flow," Journal of Nanofluids, 2021, In Press.

[2] I. L. Animasaun, S. Yook, T. Muhammad, and A. Mathew, "Dynamics of ternary-hybrid nanofluid subject to magnetic flux density and heat source or sink on a convectively heated surface," Surfaces and Interfaces, vol. 28, Article ID 101654, 2022.

[3] X. Sun, I. L. Animasaun, K. Swain, N. A. Shah, A. Wakif, and P. O. Olanrewaju, "Significance of nanoparticle radius, interparticle spacing, inclined magnetic field, and space-dependent internal heating: the case of chemically reactive water conveying copper nanoparticles," ZAMM-Journal of Applied Mathematics and Mechanics, Article ID e202100094, 2021.

[4] M. Sheikhpour, M. Arabi, A. Kasaeian, A. Rokn Rabei, and Z. Taherian, "Role of nanofluids in drug delivery and biomedical technology: methods and applications," Nanotechnology, Science and Applications, vol. 13, pp. 47-59, 2020.
[5] K. V. Wong and O. De Leon, "Applications of nanofluids: current and future," in Nanotechnology and Energy, pp. 105-132, Jenny Stanford Publishing, Dubai, UAE, 2017.

[6] F.-C. Li, J.-C. Yang, W.-W. Zhou, Y.-R. He, Y.-M. Huang, and B.-C. Jiang, "Experimental study on the characteristics of thermal conductivity and shear viscosity of viscoelastic-fluidbased nanofluids containing multiwalled carbon nanotubes," Thermochimica Acta, vol. 556, pp. 47-53, 2013.

[7] L. Syam Sundar, M. T. Naik, K. V. Sharma, M. K. Singh, and T. C. Siva Reddy, "Experimental investigation of forced convection heat transfer and friction factor in a tube with Fe3O4 magnetic nanofluid," Experimental Thermal and Fluid Science, vol. 37, pp. 65-71, 2012.

[8] J. C. Yang, F. C. Li, W. W. Zhou, Y. R. He, and B. C. Jiang, "Experimental investigation on the thermal conductivity and shear viscosity of viscoelastic-fluid-based nanofluids," International Journal of Heat and Mass Transfer, vol. 55, no. 11-12, pp. 3160-3166, 2012.

[9] A. R. Sajadi and M. H. Kazemi, "Investigation of turbulent convective heat transfer and pressure drop of $\mathrm{TiO}_{2} /$ water nanofluid in circular tube," International Communications in Heat and Mass Transfer, vol. 38, no. 10, pp. 1474-1478, 2011.

[10] C. Kleinstreuer and Y. Feng, "Experimental and theoretical studies of nanofluid thermal conductivity enhancement: a review," Nanoscale Research Letters, vol. 6, no. 1, p. 229, 2011.

[11] M. Kalteh, A. Abbassi, M. Saffar-Avval, and J. Harting, "Eulerian-Eulerian two-phase numerical simulation of nanofluid laminar forced convection in a microchannel," International Journal of Heat and Fluid Flow, vol. 32, no. 1, pp. 107-116, 2011.

[12] S. Kondaraju, E. K. Jin, and J. S. Lee, "Investigation of heat transfer in turbulent nanofluids using direct numerical simulations," Physical Review E, Statistical, Nonlinear, and Soft Matter Physics, vol. 81, no. 1, Article ID 016304, 2010.

[13] S. Özerinç, S. Kakaç, and A. G. Yazıcıoğlu, "Enhanced thermal conductivity of nanofluids: a state-of-the-art review," Microfluidics and Nanofluidics, vol. 8, no. 2, pp. 145-170, 2010.

[14] V. I. Terekhov, S. V. Kalinina, and V. V. Lemanov, "The mechanism of heat transfer in nanofluids: state of the art (review). Part 1. synthesis and properties of nanofluids," Thermophysics and Aeromechanics, vol. 17, no. 1, pp. 1-14, 2010.

[15] M. Chandrasekar and S. Suresh, "Determination of heat transport mechanism in aqueous nanofluids using regime diagram," Chinese Physics Letters, vol. 26, no. 12, Article ID 124401, 2009.

[16] A. Behzadmehr, M. Saffar-Avval, and N. Galanis, "Prediction of turbulent forced convection of a nanofluid in a tube with uniform heat flux using a two phase approach," International Journal of Heat and Fluid Flow, vol. 28, no. 2, pp. 211-219, 2007.

[17] Z. Xiao-Feng and G. Lei, "Effect of multipolar interaction on the effective thermal conductivity of nanofluids," Chinese Physics, vol. 16, no. 7, pp. 2028-2032, 2007.

[18] S. E. B. Maïga, S. J. Palm, C. T. Nguyen, G. Roy, and N. Galanis, "Heat transfer enhancement by using nanofluids in forced convection flows," International Journal of Heat and Fluid Flow, vol. 26, no. 4, pp. 530-546, 2005.

[19] G. Roy, C. T. Nguyen, and P. R. Lajoie, "Numerical investigation of laminar flow and heat transfer in a radial flow cooling system with the use of nanofluids," Superlattices and Microstructures, vol. 35, no. 3-6, pp. 497-511, 2004. 
[20] Y. Xuan and Q. Li, "Investigation on convective heat transfer and flow features of nanofluids," Journal of Heat Transfer, vol. 125, no. 1, pp. 151-155, 2003.

[21] P. Keblinski, S. R. Phillpot, S. U. S. Choi, and J. A. Eastman, "Mechanisms of heat flow in suspensions of nano-sized particles (nanofluids)," International Journal of Heat and Mass Transfer, vol. 45, no. 4, pp. 855-863, 2002.

[22] J. A. Eastman, S. U. S. Choi, S. Li, W. Yu, and L. J. Thompson, "Anomalously increased effective thermal conductivities of ethylene glycol-based nanofluids containing copper nanoparticles," Applied Physics Letters, vol. 78, no. 6, pp. 718-720, 2001.

[23] Y. Xuan and Q. Li, "Heat transfer enhancement of nanofluids," International Journal of Heat and Fluid Flow, vol. 21, no. 1, pp. 58-64, 2000.

[24] S. Lee, S. U.-S. Choi, S. Li, and J. A. Eastman, "Measuring thermal conductivity of fluids containing oxide nanoparticles," Journal of Heat Transfer, vol. 121, no. 2, pp. 280-289, 1999.

[25] T. Chinyoka, "Comparative Response of Newtonian and nonNewtonian fluids subjected to exothermic reactions in shear flow," International Journal of Algorithms, Computing and Mathematics, vol. 7, no. 3, pp. 1-19, 2021.

[26] I. E. Ireka and T. Chinyoka, "Analysis of shear banding phenomena in non-isothermal flow of fluids governed by the diffusive Johnson-Segalman model," Applied Mathematical Modelling, vol. 40, no. 5-6, pp. 3843-3859, 2016.

[27] T. Chinyoka, S. P. Goqo, and B. I. Olajuwon, "Computational analysis of gravity driven flow of a variable viscosity viscoelastic fluid down an inclined plane," Computers \& Fluids, vol. 84, pp. 315-326, 2013.

[28] T. Chinyoka, "Poiseuille flow of reactive phan-thien-tanner liquids in 1D channel flow," Journal of Heat Transfer, vol. 132, no. 11, 2010.

[29] T. Chinyoka, "Viscoelastic effects in double-pipe single-pass counterflow heat exchangers," International Journal for $\mathrm{Nu}$ merical Methods in Fluids, vol. 59, no. 6, pp. 677-690, 2009.

[30] T. Chinyoka, "Computational dynamics of a thermally decomposable viscoelastic lubricant under shear," Journal of Fluids Engineering, vol. 130, no. 12, 2008.

[31] E. R. El-Zahar, A. M. Algelany, and A. M. Rashad, "Sinusoidal natural convective flow of non-Newtonian nanoliquid over a radiative vertical plate in a saturated porous medium," IEEE Access, vol. 8, pp. 136131-136140, 2020. 